\title{
Urs Luterbacher* and Carmen Sandi Breaking the Dynamics of Emotions and Fear in Conflict and Reconstruction
}

\begin{abstract}
This paper is all about the construction of a new analytical framework to understand conflict and cooperation both at the international and at the domestic level with the aim of then finding mechanisms to reduce tensions and initiate conflict resolution schemes. The existing research literature on such analytical frameworks has so far been conducted a) mostly on standard social science disciplinary lines and has not incorporated the important work done on these questions by neuro-scientists and behavioral geneticists and $b$ ) is not really capable except in very specific instances to deal with the evolving dynamics of conflict and cooperation. Conflict over scarce resources (territory, mates, food) between members of the same species is a universal feature of evolution. Often conflict, especially armed conflict is supposed to be due to shows of force by two or more parties in order to appropriate or dominate resources. Force appears thus not to be the only decisive factor; perceived entitlement and powerful feelings of injustice thereby generated in the case of challenge, extended to group identity are also at the basis of conflict and aggression in humans. The relationship between environment and conflict, the role of emotions such as fear, and the absence of clear definition and enforcement of property rights within societies are also factors in the development of conflict. Thus we have here developed an
\end{abstract}

Article note: The research presented here was supported through a grant from SNIS the Swiss Network for International Studies. This help is gratefully acknowledged by the authors.

Prepared for the

Workshop on:

Advances in Defense \& Peace Economics and Peace Science

November 8 - 11, 2013

Host:

Institute of Defense Economics and Management

Central University of Finance and Economics

39 South College Road, Haidian District

Beijing, China

*Corresponding author: Urs Luterbacher, Political Science and International Relations, Centre for Finance and Development, and Graduate Institute of International and Development Studies, Geneva, Switzerland, E-mail: urs.luterbacher@graduateinstitute.ch Carmen Sandi: Brain Mind Institute, Behavioral Genetics Laboratory Federal Institute of Technology, Lausanne, Switzerland 
analytically based numerical model that aims to include finding on these topics by Neuroscience and to emphasize the role of emotions in conflict and cooperation dynamics. This model has been simulated without specific reference to a particular country with the result that economic conditions drive our system since in one case sustained growth produces stability and end of combats whereas deteriorating capital growth and GDP collapse lead to increased hostile coalition participation and more fighting. However, the mere trigger of economic conditions is insufficient to explain conflict escalation, which results from increased participation in mutually hostile coalitions and greater fighting propensity where emotions such as fear and resentment play their role. Finally a detailed empirical analysis of the current Syrian conflict has been undertaken which shows the ability of the model to forecast actual historical developments. This study also indicates that worsening economic conditions are not the only triggering factors in civil conflict. Perceptions of opportunities due to a weakening of a regime's authority also play a major role.

Keywords: anger, conflict, cooperation, emotions, fear, escalation, reciprocity

DOI 10.1515/peps-2014-0015

\section{Difficulties of negotiation and conflict resolution}

Conflict over scarce resources (territory, mates, food) between members of the same species is a universal feature of evolution. Often conflict, especially armed conflict is supposed to be due to shows of force by two or more parties in order to appropriate or dominate resources. Conflicts and warfare with their high costs and dubious rewards are however difficult to rationalize even though they seem to continue to occur: The choice of the use of force is taken despite the fact that it often leads to very uncertain outcomes. Force appears thus not to be the only decisive factor; perceived entitlement and powerful feelings of injustice thereby generated in the case of challenge, extended to group identity are also at the basis of conflict and aggression in humans. Some evidence for this is available from research on animal behavior: Stress contributes to social imbalance (Cordero and Sandi 2007).

The relationship between environment and conflict, the role of emotions such as fear, and the absence of clear definition and enforcement of property 
rights within societies are also factors in the development of conflict and sometimes genocide (Luterbacher and Krasna 2010). The development of weapons and complex forms of social organization allowing group cooperation in aggression have turned simple dominance contests into a spiral of ever more complex conflict mechanisms that are exceedingly difficult to control. Evidence for these can be seen in some until now unsolvable confrontations such as the Israeli Palestinian or the Pakistan Indian one. Furthermore, the existence of protracted fighting in many domestic contexts such as in Lebanon, Afghanistan or Iraq show the problem of negotiating an end to such confrontations and then building institutions that will maintain domestic peace over long periods of time. This seems to be the case despite evidence showing that generalized reciprocity mechanisms can lead to cooperation in animal and human societies (Axelrod 1980; Rutte and Taborsky 2007).

\section{Puzzles}

These considerations lead to the formulation of several puzzles both empirical and theoretical. One can observe that often relations between human groups tend to be relatively peaceful until some triggering event leads to violent conflict like the example of former Yugoslavia shows. Moreover, even if conflict occurs among some groups, it does not always escalate into forms of extreme violence. For instance, even though the Indian Union is composed of several ethnic groups and religious entities, for the moment the clashes that have occasionally occurred between these have not evolved into more intense forms of conflict and destroyed the whole fabric of that society. Finally, as shown in the work of Fearon (1994) and Fearon and Laitin (1996), conflict initiation is hard to rationalize if its issue is uncertain and if its evolution leads to costly and most of the time irrevocable investments. A similar observation can be made about strikes. Nevertheless conflicts and strikes occur but as emphasized previously not necessarily. This leads to the idea that a significant clue to solve these puzzles must lie in the dynamics of the conflict themselves. In such dynamics emotions, stress and fear might play a significant role. As shown in Luterbacher and Krasna (2010), fear to be overwhelmed by the other ethnic group played a significant role in the massacre of Tutsis and moderate Hutus in Rwanda in 1994. How can such dynamics better be understood? We believe that a static framework of analysis cannot account for such developments and a dynamic perspective has to be introduced at the analytical level as well. However, in order to be able to work out such a dynamic perspective, basics of decision-making in conflict and in cooperation have to be revisited. 


\section{Decision making}

Conflict and cooperation issues can be framed in terms of individual or collective decision making: One can describe an individual or a collective in terms of a decision process that results into initiating or responding to conflictual moves of an opponent or conversely to seek a more peaceful and cooperative outcome and thus not to escalate aggression but rather to diffuse it and to foster collaboration. Among the explanatory schemes put forward to understand such decision processes rational choice approaches have always played an important role in the economic and political science literature. A traditional way to consider this problem takes for granted 1) that decision-makers are essentially risk neutral, occasionally weakly risk averse preference and utility maximizers, and 2) that probabilities about crucial outcomes such as winning wars or the costs associated with them are essentially given by nature and are not based on subjective estimates by the parties involved. The same can be said about types (usually hard or soft) that protagonists to a conflict are supposed to represent: They are assumed to be given by a random draw out of a predetermined probability distribution. The resulting theory of conflict and war is relatively simple: war may occur because two parties do not have complete information about each other's means or each other's preferences. Moreover, within the framework of incomplete information, fighting involves taking short-term losses but may help creating a reputation that will keep opponents away in the future. While such reputation building is certainly plausible, it is sometimes hard to figure out when very weak powers nevertheless confront very strong ones (re. the Israel Palestinian conflict and the two successive Intifadas). Moreover, to work, it requires the introduction of the notion of commitment that is supposed to overcome the reluctance decision-makers might have for costly actions. Why certain categories of decision makers choose to commit and others do not is again left to a random selection of types left to nature.

In other words, the framework that is provided so far by this type of literature over emphasizes information problems and results in a relatively static view of conflict and cooperation processes where most of the relevant parameters are supposed to be determined before they start. The incorporation of emotional components of conflict and cooperation as well as their dynamic interaction effects such as tit for tat responses in aggressive escalatory moves requires a revision of these standard explanatory schemes. In particular, they lead to the question if traditional rational choice theories are adequate in representing escalatory evolutions well. An agent, according to our conception, can be rational and all of a sudden stop cooperating, if pressured too much, and initiate conflict. This choice for conflict should thus be included as equilibrium behavior. On the other 
hand, cooperative behavior could also result from the recognition by opponents that pressuring the other side too much might result in an equilibrium in conflict, an outcome that is best avoided. The perspective evoked here differs thus from the one based purely on incomplete information about the type of another agent. In some sense we are seeking to explain the choice of a gamble that might lead to a conflict with a chancy outcome, which is determined endogenously by the succession of moves and counter-moves that agents engage in. One should also account for the fact that once conflict has started it can result in an escalatory process that is difficult to stop and is likely to generate costs beyond all initial estimates before it finally ends. This conflict or "war trap" outcome should be used to explain situations that are not included in the classical conception, which focuses exclusively on war initiation. In our view, war initiation is just part of the story. If it were the only puzzle to explain then armed conflicts would not necessarily lead to tragic consequences since a few battles or even skirmishes would be sufficient to establish the superiority or equality between two bargainers who decide to fight it out. That these bargainers have incentives to escalate and then to keep fighting is what a new approach to rationality should help to establish. In order to proceed with the proposed revision of standard explanatory frameworks that we want to undertake here, a clarification of the links between emotions and conflict as seen by neuro-science and behavioral genetics is necessary.

\section{Emotionality, conflict resolution and aggression}

Conflicts between different parties (individuals, groups, nations) are rarely devoid of eliciting deep emotions in the respective opponents. From an evolutionary point of view, negative emotions linked to social confrontations, such as anxiety, anger and disgust evolved by facilitating the avoidance of similar dangers during our species' development (Hofer 1995). They alerted the individual to existing threats and indicated that defensive actions are needed (Gilbert 2001; Nesse 1999). Price et al. (2004) included anger with assertiveness as an escalatory emotion, associated with the escalation of conflict. In contrast, positive affects evolved in the context of success, safeness and security (Gilbert 2001).

The end of a conflict may, through reconciliation of the two parties, bring relief by decreasing the level of negative affect and/or by increasing the level of positive affect. When dominant contests are clearly resolved, the dominant part generally feels rewarded and reassured on its dominance quality, while the loser part can either accept defeat and progressively adapt to the situation (and from there on engage in other tasks) or enter into a "maladaptive" cycle characterized 
by high negative emotionality (i.e., anxiety, anger go into overdrive by operating at a greater intensity and/or over a prolonged period of time). In many occasions, the part facing inevitable defeat may remain in "fight mode" associated to a feeling of injustice or unfairness (Collins 2008). This fight mode frequently represents a need for "retaliation." When there is a failure of reconciliation due to external constraints (such is frequently the case with the current organization of our society) to the open resolution of conflicts among rivals, with the conflict enduring in an unresolved state, emotional escalation is generally observed in both parts. Unfairness is generally felt by both opponents. Lack of conflict resolution is associated with a mutual feeling of loosing something that each part respectively feels as genuinely belonging to them (identification process of the contestants with the disputed goal). While the conflict is not solved, each part is under the threat of experiencing a big loss (which in psychological terms would bring increased and sustained anxiety). Unsatisfactory attempts to negotiate can bring escalation of high negative emotionality (i.e., anxiety, anger) to both parts. In all these cases, high negative emotionality operates as a main obstacle to achieve the resolution of the conflict. In most conflict cases, for rational approaches to succeed towards conflict resolution, high negative emotionality needs to be truly overcome.

Emotions are also at the core of violence. The most ubiquitous emotion in situations of violent threat is confrontational tension/fear (Collins 2008). Some authors emphasize the fact that violence is difficult, not easy. In their view, for violence to happen, the situation must present a way for at least some participants to circumvent confrontational tension/fear (Collins 2008). In human populations, there are two main ways of addressing violence: (i) hot emotional violence, with the most typical emotion being anger. However, the mere presence of a hot emotion is not enough for successful violence to occur; the hot emotion needs to be configured in such a way across the group so that confrontational tension/fear is overcome; (ii) cool technical violence, in which the violent activists manage their own emotions and take advantage of the emotional weaknesses of their opponents. In reality, conflicts can have combinations of hot and cold approaches

\section{Evolutionary basis of emotionality}

In Neuroscience, the view is emerging that much of human mental activity is driven by the ancient affective emotional and motivational brain systems shared with other animals (Gardner and Wilson 2004). It is now clear that all 
mammalian brains share a large number of basic emotional systems (Panksepp 2005). Since core emotional tendencies seem to emerge from ancient brain processes shared by all mammals, this effectively allows one to utilize cross-species evolutionary strategies, relying on animal brain-behavior models. We should be able to shed light into core human emotional tendencies by studying animal brains (Panksepp 2005). Therefore, one can define specific emotional traits that can be studied in nonhuman mammals.

Mammalian brains contain circuits that are critically involved in basic emotions, including anger (provoked when organisms do not get what they want), fear, separation distress and social bonding (Panksepp 2006). These circuits appear to be homologous across all mammalian species. An example is given by the aggression level and dominance hierarchy established between two male rats when stress (a fear-induction experience) is given to one of the two rats in the contest. In our model, a social hierarchy established by two male rats during a first encounter is not maintained one week later. If one of the two rats is stressed, the stressed rat becomes subordinate and the hierarchy that is formed is maintained. In addition, we have evaluated the role of "intrinsic stress" (i.e., high anxiety trait) in the formation of the social hierarchy and found that high anxiety trait predicts (60-75\%) the development of social subordination when the contest is hold with a low anxious individual. Thus, we have shown that stress can have a deleterious impact in individuals' position in the social scale, as well as increasing social inequality.

In contrast to the difficulty of evaluating and manipulating these systems in humans, it is by far easier to explore them systematically (e.g., their neural circuitry, molecular and gene determinants, physiological and behavioral correlates) in animal models. It is, therefore, essential to integrate the animal and human work to make optimal progress on the most interesting variables in such analyses. Thus, the use of animal models is considered to be an excellent tool to help clarifying the foundational nature of the human mind (Panksepp 2006).

\section{Evolutionary basis of cooperation}

Reciprocity has been frequently proposed as a mechanism to explain the evolution of cooperation between unrelated individuals (Trivers 1971). There are different forms of reciprocity: (i) direct reciprocity, in the form of tit-for-tat, that can lead to the evolution of cooperative behaviors when individuals return one favor with another (Axelrod and Hamilton 1981); (ii) indirect reciprocity, in which 
individuals cooperate with other individuals that they have previously seen engaging in cooperation with others (Nowak and Sigmund 1998a,b, 2005); (iii) generalized reciprocity, in which an individual cooperates if it has experienced cooperation before, regardless of the identity of the partner (Hamilton and Taborsky 2005; Pfeiffer et al. 2005; Rutte and Taborsky 2007). Both direct and indirect reciprocity require highly advanced cognitive abilities (Dugatkin 2002), in which individuals must recognize a cooperating individual, and use this information to act accordingly. However, generalized reciprocity only relies on information from the previous interaction, and therefore it does not require sophisticated cognitive abilities.

In rats, evidence for both generalized (Rutte and Taborsky 2007) and direct (Rutte and Taborsky 2008) reciprocity has been reported. Generalized reciprocity was shown in form of cooperative behavior influenced by prior receipt of help, irrespective of the identity of the partner (Rutte and Taborsky 2007). In the study, rats that were trained in an instrumental cooperative task (pulling a stick in order to produce food for a partner) pulled more often for an unknown partner after they had been helped than if they had not received help before. Direct reciprocity was also shown in the form of a higher propensity of rats to cooperate with a known partner who had helped them before (Rutte and Taborsky 2008). Levels of cooperation observed in this case were higher (50.7\%) than for generalized reciprocity. Theoretical models have shown that the expression of direct reciprocity in a population will induce the evolution of generalized reciprocity (Nowak and Roch 2007), bringing about much higher levels of cooperation overall.

Given that no special cognitive abilities are required for generalized reciprocity, as individuals only need to remember and act regarding their own last experience with any partner, it has been suggested that the underlying neurobiological mechanisms can be rather simple hormonal or neuronal mechanisms (Rutte and Taborsky 2007). Generalized reciprocity is functionally related to the winner and loser effects, where anonymous social experience also influences behavior in subsequent interactions, and the neurobiological mechanisms underlying winner/loser effects and generalized reciprocity might be similar (Singer et al. 2004). Hormonal changes experienced under socio-positive or socio-negative experiences may critically affect the tendency to cooperate. Recently, oxytocin was shown to influence pro-social behavior in human (Baumgartner et al. 2008; Kosfeld et al. 2005; Zak et al. 2005) and rats (Uvnas-Moberg 1998). Vasopressin is a similar small neuropeptide that also plays strong roles in social and affective behaviors (Meyer-Lindenberg 2008). Thus, oxytocin was shown to limit the fear of betrayal in social interactions, in line with animal data showing that it inhibits defensive behavior and facilitates maternal behavior and pair-bonding (Mendres and de Waal 2000). Striatal areas, more generally linked with reward processing, have been suggested to play a role in mutual cooperation (Fehr and Camerer 2007; 

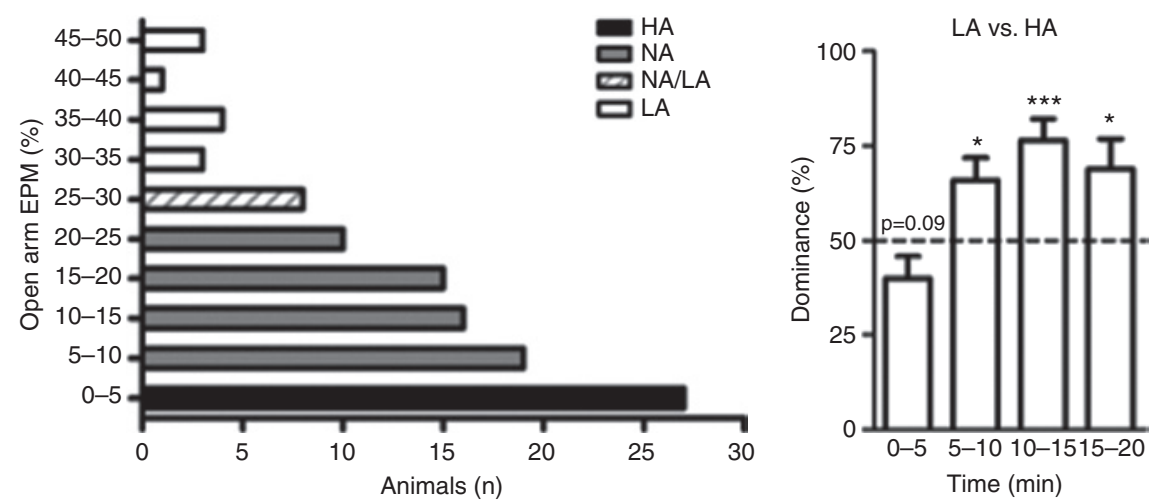

Figure 1: Left panel: Rats' distribution into different anxiety groups. Right panel: Dominance in percentage. HA: high anxiety; LA: low anxiety; NA: normal anxiety.

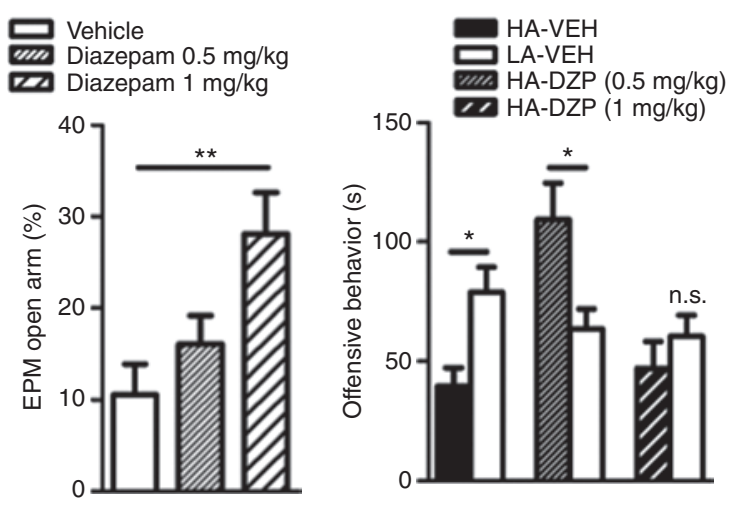

Figure 2: Left panel: Effect of different diazepam (DZP) doses given systemically in the elevated plus maze (EPM). Right panel: Offensive behaviors in HA-LA interactions when the HA animal is injected with DZP. HA: high anxiety; LA: low anxiety. VEH: vehicle.

Zak et al. 2005). However, existing knowledge about the neurobiological mechanisms underlying these complementary social processes is scarce.

Timmer et al. (2011) show that anxiety trait is highly predictive for social dominance; highly anxious (HA) animals tend to become submissive during an encounter when matched for weight to low anxious (LA) conspecifics as apparent from both total duration of offensive behavior (Figure 1, right panel).

Systemic administration of the anxiolytic drug Diazepam (known better by its commercial name, Valium) reduces anxiety on the EPM (Figure 2, left panel) while it enhances dominancy (absolute and relative) in HA rats (Figure 2, right panel). 
These findings indicate a very strong role for anxiety-like personalities in the resolution of social conflicts linked to the establishment of hierarchies. They also show that anxiolytic drugs can change the outcome of a social encounter. Altogether, these observations provide key information to interpret dynamics of social interactions.

\section{Agent based modeling}

Given some of the weaknesses that we have pointed out concerning the existing rational choice conceptions of conflict and cooperation, new ways of representing decision making about aggression and collaboration have been presented under the general framework of computational agent based modeling. These will also integrate some of the major findings of the neuro-science research outlined above and tested in animal populations Instead of relying on the traditional expected utility model which involves a description of two protagonists or assumes that all parties have similar preference functions, this type of approach is set on developing computer models of interacting agents which can be given similar or different characteristics. In this context, the contribution by Bhavnani and Backer (1999) appears to be particularly elaborate because they are trying to build on previous formulations developed by political scientists on ethnic conflict. The emphasis of that earlier work by Fearon and Laitin (1996) and Lohmann (1993) is centered on information questions. Conflict will be initiated or amplified by information circulating mostly within one group and directed against the other. Misperceptions about the other group can lead to armed violence. As specified by Bhavnani and Backer (1999, 11): “agents belong to one of two ethnic groups: group $A$ or group $B$. As a matter of convenience, we let group $A$ represent the ethnic group in power and group $B$ the rival ethnic group. Depending upon the circumstances, either group could be a minority. We define $\mathrm{q}$ as the proportion of group $A$ in the overall population. At time $t$, every member of group $A$ has a probability of following the ethnic cue $(E)$ and of refraining from following the ethnic cue $(R)$. The balance of probabilities depends on the type of message that is transmitted, the individual's level of extremism ..., and the strength of any metanorm. ${ }^{1}$ The metanorm dictates that any member ai who fails to follow the ethnic cue when the message is national is killed by another member $a j$ with a probability of $m$."

1 A metanorm is according to Axelrod (1986) a norm that serves to enforce a group norm, here the agent who does not follow the ethnic cue of the group he belongs to will be punished himself. 
Without denying the importance of information questions in the generation of armed conflict, one can nevertheless legitimately ask about the importance of other factors especially in the context of developing or emerging countries. Quite a few authors (Andre and Plateau 1998; Collier and Hoeffler 2000; Homer-Dixon 1994) have pointed out the importance of resource issues in explaining conflict at least as a long-term factor. Information issues raised by Bhavnani and Backer are considered without reference to a specific context. However, context matters and in the case of the Rwandan genocide for instance as in others fear particularly about losing the control of important resources appears to be a powerful motivator for extreme behavioral responses in general and for conflict and violence in particular. These objections show that so far agent based computational modeling has not moved much beyond some of the restrictive assumptions of traditional rational choice modeling in the sense that it also tends to stick to a rather static characterization of individual behavior. In addition it tends sometimes to ignore contextual information such as reaction to evolving actions of others or the evolution of the agent's resource base. In contrast, Cederman $(2003,2005)$ has attempted to construct computational models that reflect much more closely the contextual base of agent's behavior in conflicts and showed therefore that introducing more complex representations within this general framework is possible. Agent based modeling remains thus an important and promising alley for the representation of conflict behavior even though more variety and flexibility as well as the possibility to include dynamic feedback interactions into it have to be incorporated into it.

\section{Overall conceptual difficulties}

In the social and especially political science literature on conflict, the integration between emotional and rational choice explanations of conflict is poorly realized. Superficially, these two factors, emotions and reason seem to be at opposite ends of an explanatory spectrum. However, a common ground can be found if one follows the intuition that emotions are associated with rare and unusual events such as serious threats to existence or the prospect of severe losses of wealth or physical, property, territory or physical integrity. Such considerations are important if one wants to model decision-making behavior accurately.

Rational choice, particularly expected utility approaches have been poor at dealing with such situations. Early axiomatizations of expected utility theory such as those put forward by von Neumann and Morgenstern (1947) or Friedman and Savage (1948), essentially ignored the issue. It was the merit of the 
French economist Maurice Allais (1953) to have raised the problem of taking into account rare or very constraining events. He illustrated his criticism of the traditional approaches with the following anecdote: If a traveler is caught in Marseilles with a minimal amount of money not sufficient to buy a ticket and has to reach Paris imperatively, any gamble that will give him the greatest probability of winning more than the price of his ticket will be worth entering into regardless of absolute utility maximization procedures. Allais' considerations led to the formulation of the well-known Allais paradox in the literature. To take these issues into account Chichilnisky (2009a) has developed a new axiomatic system that can deal with extreme or unusual events so called "black swans" in order to account for attitudes involving fear of catastrophes. She has in particular been able to show that her new axiomatic is capable of including both normal and unusual events into a single analytical framework. A similar approach is taken in the so-called Rank dependent Expected Utility Theory due originally to Quiggin (1982) but then developed among others by Chateauneuf, Cohen, and Meilijson (2005). The psychologists Kahneman and Tversky (1979) through their development of "prospect theory" have shown that Allais' considerations were backed by empirical observations and that decisions in uncertain situations are taken under two general perspectives: 1 . Ordinary individuals tend to be risk averse under the prospect of gains and risk preferring under the prospect of losses. 2. They tend to overestimate the likelihood of low probability events and underestimate the likelihood of high probability ones. Fearful reactions are often motivated by the prospect of losses associated with some specific event either natural or social: A natural catastrophe or a massive social upheaval will lead to risky gambling and make conflict outcomes more likely despite their own prospective high costs. In addition, the analysis of escalation processes started by Martin Shubik (1971) and pursued by Barry O’Neill (1986) with the dollar auction game constitutes an attempt to deal explicitly with the rational analysis of conflict dynamics and to show that even rational moves may lead to irrational outcomes.

Also contextual evolutions of social interactions such as environmental change are often caused by a combination of natural and social forces. Human activities can lead to overuse of natural resources which then result in scarcities and these scarcities can then lead to emotional reactions and thus to taking risky gambles and to conflict. Given the fact that the empirical evidence about the relations between environment and conflict is ambiguous, it suggests that the link between the two issues only makes sense and works whenever institutional factors such as the clear definition and enforcement of property rights are absent or weak within or across societies and thus when fear about property losses motivates individuals and groups to act aggressively. 


\section{Basic model}

This basic model builds on previous research by Luterbacher and Norrlof (2008) and Chichilnisky (2009b) and Chichilnisky et al. (2000). The objective of the model is first to combine some of the various strands of theory that have been used to explain conflict: Among those the contributions by Bhavnani and Backer (1999) and Bhavnani et al. (2011) appears to be particularly elaborate because they are trying to build on previous formulations developed by political scientists on ethnic conflict. The emphasis of that earlier work by Fearon and Laitin (1996) and Lohmann (1993) is centered on information questions. Conflict will be initiated or amplified by information circulating mostly within one group and directed against the other. Misperceptions about the other group can lead to armed violence. To this Bhavnani et al. (2011) add a particular concern about the location of conflict and how violence is territorially determined ${ }^{2}$ and influenced by social distance. Without denying the importance of information questions, territoriality and social distance in the generation of armed conflict, one can nevertheless legitimately ask about the importance of other factors. Quite a few authors (Andre and Plateau 1998; Collier and Hoeffler 1998, 2000; Homer-Dixon 1994) have pointed out the importance of resource issues in explaining conflict at least as a long-term factor. Information issues raised by Bhavnani and Backer (1999) and Bhavnani et al. (2011) are considered without reference to a specific context. However, context matters and in several cases of conflict both domestic and international fear appears to be a powerful motivator for extreme behavioral responses in general and for conflict and violence in particular. Such behavioral responses appear irrational at the outset and cannot usually be explained through standard models of decision making such as expected utility as shown convincingly by Chichilnisky (2009b). ${ }^{3}$ Quite clearly, fear is also closely linked to rumor and thus often to false information transmissions. Moreover, fear has a tendency then to build upon itself and to influence thus conflict dynamics: Fear of the other will lead to suppress the other violently, which will then in reaction draw more people who feel threatened to rally toward him as much as opponents will rally against him. Fear and other "emotional" factors in conflict such as a feeling of injustice are precisely what neuroscience research has emphasized. How can one now tie all these aspects together?

2 Such a territorial emphasis and the relationships it implies between armed groups and the civilian population has been pioneered by Kalyvas (2006) Kalyvas and Kocher (2009).

3 She suggests an alternative axiomatization of utility theory topology as already mentioned above in order to account for attitudes involving fear of catastrophes. 
A numerical agent based model will provide numerical solutions, which can then be confronted and calibrated with empirical data.

\section{Fundamental economic relations}

We formulate the model in terms of an agent-based perspective. We take this approach while we remain able to explore some of the relations we want to emphasize with purely analytical methods. We postulate a utility function for a representative agent $i$ as:

$$
u_{i}\left(x_{i}, \sum_{j=1}^{N} g_{i}\right)=\exp \left(\alpha-\frac{1}{x_{i}}+\frac{-1}{\sum_{j=1}^{N} g_{i}}\right)
$$

where $x_{i}$ is a private good and $g_{i}$ a public or collective good and $\alpha$ an adjustment parameter. The shape of this utility function is quite important in the present context because it is concave with respect to the origin for higher levels of utility but convex for lower ones, it is in other words an S curve like the following Figure 3:

Standard assumptions about rational behavior assume often, in contradiction with the empirical evidence, that most preference schemes whether individual or collective can be described as either risk neutral or risk averse. These premises are established usually for mathematical convenience, to simplify complex issues and reduce them to simple linear ones. Experimental psychologists and even observers of animal behavior have noticed that risk preference

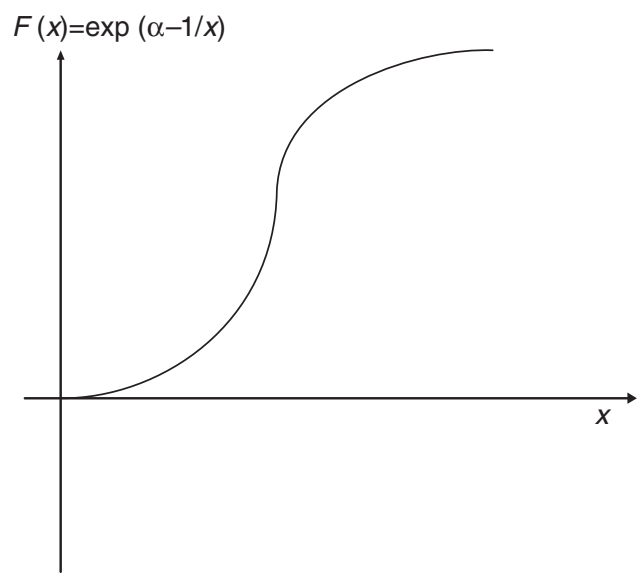

Figure 3: Exponential S-shaped One Variable Utility Function. 
often appears after risk aversion when a decision maker is faced with the prospect of losses (Stephens 1990). Risk aversion and risk preferring behavior are regularly seen together, and various attempts have been made to explain their joint appearance. The principal analyses of hybrid risk attitudes are Battalio et al. (1985, 1990), Camerer (1989), Fishburn and Kochenberger (1979), and especially Kahneman and Tversky (1979). In particular, Fishburn and Kochenberger (1979) show that the majority of individuals have an everywhere increasing utility function $u(x)$, where $x$ is a measure of gains and losses that increases more than proportionally for small or negative $x$ and then less than proportionally for relatively high values of $x$. Most individuals are thus risk averse over gains and risk preferring over losses. This notion can serve as a theoretical justification for the contention elaborated by Hirshleifer (1991) that the poor have a comparative advantage in appropriation, obviously a more risky way to acquire wealth than capital accumulation through savings. In general, this type of utility function leads to very different but also quite plausible bargaining behavior as compared to traditional models. ${ }^{4}$ In particular, the fact that individuals are risk preferring against losses translates the crucial psychological importance of the fear to loose something that one has acquired and thus reflects the "emotional" aspect of their decision making. Here emotional drivers produce rash (though not irrational) behavior. As has been demonstrated by Arcand and Luterbacher (2013), a similar approach to this one consists in postulating that each agent has a probability weighting function that distorts his or her perception of the likelihood of events as emphasized by the Rank Dependent Expected Utility (RDEU) theory due originally to Quiggin (1982). In this case a linear utility function suffices in describing the preferences of an agent. The two conceptions lead to equivalent results. Moreover, a conflictual bargaining situation may in this case end up as equilibrium in conflict, which can have lasting effects (cf. again Arcand and Luterbacher 2013).

If we make the assumption that all representative agents in a society are identical, an equilibrium can be expressed by a symmetrical allocation among all $N$ agents of the society (there is only one such equilibria as mentioned by Dasgupta and Heal 1979, 42). If all agents in society maximize utility in the same way $i$ does, based upon some expectation they have on how much of the collective good every other agent produces or purchases, a particular kind of Nash equilibrium obtains for the society in question, which we will call a society market or anarchic equilibrium. In other words, if every agent anticipates the purchase or production of the amount of collective good $g$ by every other agent, for agent $i$, the problem is then to maximize:

4 The links between bargaining and risk attitudes are explored as mentioned before in Arcand and Luterbacher (2013). 


$$
\exp \left\{\alpha-\frac{1}{x_{i}}+\frac{-1}{\left[g_{i}+(N-1) \hat{g}\right]}\right\}
$$

which is just a reformulation of utility function (1) with the assumptions enumerated above.

Maximizing (2) is subject to the budget constraint established as follows: Assume that initially agents have one unit of the private good $x_{i}$, and none of the collective good $g_{i}$. Agents are however able to convert the private good into the collective good at a rate $p^{s}$. If $s=1$, the private good can be transformed into the collective good proportionally, if $s<1$, the conversion takes place more than proportionally, if $s>1$, less than proportionally. If, for instance, $g_{i}$ stands for national defense, then $s$ represents a measure of society's ability to mobilize resources for war (the lower is $s$, the greater the possibility to mobilize resources). Moreover, assume that $i$ saves a certain amount of $x_{i}$ for investment, a proportion $h$ which will be accounted for in the budget constraint.

Agent $i$ in society $g$ can therefore maximize $u_{i}$ as defined in (2) subject to the budget constraint:

$$
p^{s} g_{i}+(1+h) x_{i} \leq 1
$$

Maximizing (2) subject to (3) leads to the following equilibrium values for $x_{i}$ and $g_{i}$, i.e., and $\hat{g}$ :

$$
\hat{x}=\frac{N}{\sqrt{h+1}\left(\sqrt{p^{s}}+N \sqrt{h+1}\right)} \quad \text { and } \quad \hat{g}=\frac{1}{\left(\sqrt{p^{s}}+N \sqrt{h+1}\right) \sqrt{p^{s}}}
$$

These are not Pareto optimal as not enough quantities of the private good are converted into the public good. It is easy to compute Pareto optimal values by treating the public good as if it were a private good and going through the same optimization process as before. One gets then:

$$
\hat{x}=\frac{\sqrt{N}}{\sqrt{h+1}\left(\sqrt{p^{s}}+\sqrt{N} \sqrt{h+1}\right)}, \tilde{g}=\frac{1}{\left(\sqrt{p^{s}}+\sqrt{N} \sqrt{h+1}\right) \sqrt{p^{s}}}
$$

From there we can now calculate the distance between the Pareto optimal solution and the "anarchic" equilibrium situation as:

$$
\sqrt{p^{s}} \sqrt{h+1} \frac{(\sqrt{N}-1)^{2}}{N} \geq 0
$$


This distance can also be called $E$, the externality in the use of resources that has not been internalized through the full use of a public good. This can represent in some sense the fact that property rights are not sufficiently made clear or protected because a public good to achieve these things is not sufficiently maintained. We will thus interpret $E$ as measuring here the absence of fully defined and protected property rights. As these have important and decisive consequences for maintaining environmental goods as well as political stability, they play an important role in our conceptualization and our modeling effort. One can observe that when $N=1, E$ will always be 0 as it should be since when we have a single individual in a society all goods are private ones. We will make use of the $E$ concept later on. A further quantity to be computed is the short-term advantage an agent gets from overuse, $z$, which can be expressed by the difference in the amount of private good she gets from the anarchic equilibrium as opposed to the Pareto optimal situation. $z$ is then for positive values of the square roots:

$$
z=\frac{\sqrt{N} \sqrt{p^{s}}(\sqrt{N}-1)}{p^{s} \sqrt{h+1}+N(h+1) \sqrt{N} \sqrt{h+1}+\sqrt{N} \sqrt{p^{s}}+N \sqrt{p^{s}}+\sqrt{N} h \sqrt{p^{s}}+N h \sqrt{p^{s}}} \geq 0
$$

As can be seen $z$ is positive provided $N>1$. With $N=1$, Pareto optimal and anarchic equilibrium are trivially equivalent as they should be in the limit case.

Through time, dynamic equations can now determine evolutions of the variables $x$ and $N$ and thus also $E$ and $z$. N's evolution can be determined via a dynamic population equation:

$$
\frac{d N}{d t}=(\beta-\delta) N
$$

where $\beta$ represents a birth (eventually plus or minus migratory balance) and $\delta$ a death rate.

To get at the dynamic of private goods within a society we can first define a capital increase rate, in the following way:

$$
\frac{d K}{d t}=N h x_{i}-\rho K
$$

where $\rho$ represents an amortization rate. Quite clearly, both $h$ (savings rate) and $\rho$ (amortization) are parameters linking the present to the future and determine, in terms of capital accumulation (if it occurs), a time horizon. This time horizon is longer if existing capital is not dissipated through insufficient savings and thus investment rates with regard to amortization. 
We can now determine $N x_{i}$ through a production function such as:

$$
N x_{i}=\exp \{\zeta-\gamma / K-\eta / \omega N\} .
$$

where $\zeta$, is an adjustment parameter and $\gamma$, and, $\eta$ are elasticities of capital and labor with respect to production.

We will assume here that only a proportion $w$ of the $N$ agents are involved in production. This proportion to be specified below represents the number of agents involved in productive activities as opposed to fighting. What we intend to convey here is that when increasing segments of a society's population are involved in fighting, production will decrease since the number of producers is shrinking.

\section{Fighting propensity}

The objective of the model is to explain a representative agent's choice between producing and joining fighting forces in an unstable country. This perspective can help understand under which conditions the emergence of a society with competing warlords (as it sometimes occurs in developing countries) is more or less likely than the building of a politically stable and economically developed society. Moreover, we will try to link the question of the warlord competition to the issue of natural resources. We start from the following assumptions:

Assumption 1: We assume initially a society with $N$ identical individuals, who can be symbolized by one representative politico-economic agent. N.B. This is a standard assumption which is usually included either in purely theoretical but also agent based models.

Assumption 1a: The above assumption will be modified in a second step in such a way that the society will be divided into groupings of $N, M$ and $U$ individuals which stand for coalition kernels of factions $N$, and $M$ and a considerable quantity of uncommitted bystanders $U$ (an "ocean" of uncommitted individuals). A coalition model based upon the development of oceanic game models of coalitions will be used (more on this below).

Assumption 2: The representative politico-economic agent has the choice of how much time he wants to allocate for producing and how much for fighting. In our model this will be represented by a decision to optimize by using a certain proportion of his time to produce, and thus to contribute to a stable political regime, and by using the remaining time proportion to the establishment of a "warlord society" through fighting. 
Assumption 3: The individual choice of the representative agent is linked to the aggregate decision of the society. If our representative politico-economic agent achieves a higher expected value by fighting and vice-versa, we can expect that this outcome will eventually hold for the society as a whole. We can draw an analogy here to Schelling's binary decisions in an aggregate framework: the decision by one individual is conditioned by what all others are doing. To clarify this aspect: Each individual agent is influenced by all others in their individuality. So for instance if everybody drives to work it makes sense from an individual point of view to take public transportation because the roads are crowded. However, if most people take public transportation it is again worth driving. As shown by Moulin (1986), this condition can lead to stable or unstable Nash equilibria at the level of the whole society.

Assumption 4: Every agent is a producer/fighter and at the same time a consumer. The framework is the one of an economy, in which initially no trade with the outside is taking place but then eventually the economy opens up to trade.

Assumption 5: We assume that if the agent becomes a fighter, he can already make an initial gain at the beginning of the period by exploiting some natural resources or by getting a reward, which might be emotional or a mix of emotional and economic values. By contrast, becoming a producer demands an initial commitment, an investment, which is usually longer than any commitments the fighter has to make. This initial investment can be, for example, the cost of education or in a more agricultural society the cost of creating tools/machines for further development of productive activity. So while it is true that even a fighter has to make some initial commitments stricto sensu, lato sensu this one is usually much shorter than an investment to produce. The fighter in this sense is much closer to a gambler in his attitude.

We can show that want to find the level of producing/fighting, which maximizes the utility of a representative agent. The model is initially a static, one-period model, in which the representative agent is a utility-maximizer who chooses an individually optimal level of producing and fighting. Moreover, we can combine this with a coalition formation behavior which although implicit in the notion of social distance and communication (or absence their of used by Bhavnani et al. (2011) and Fearon and Laitin (1996) and Lohmann (1993) is never explicitly represented in all the formulations and theories about domestic conflict.

Assumption 5: We assume that if the agent becomes a fighter, he can already make an initial gain at the beginning of the period by exploiting some of the natural resources. By contrast, becoming a producer demands an initial commitment, an investment. This initial investment can be for example the cost of edu- 
cation, or in a more agricultural society the cost of creating tools/machines for further development of productive activity.

Assumption 6: We assume that the only choice made in this society is one between fighting and producing activities. We thus ignore for the moment the question of how Warlords emerge or how they organize their armies. We assume that in an environment where lots of people are willing to fight or where our representative agent devotes most of his time to fighting the emergence of warlords capable of organizing armed bands is more likely.

We want to find the level of producing/fighting, which maximizes the utility of a representative agent. The model is here a static, one-period model, in which the representative agent is a utility-maximizer who chooses an individually optimal level of producing and fighting.

The representative agent has the following aforementioned utility function:

$$
u_{w f}=\int_{i=1}^{n} c_{i}^{D} d c,
$$

where $c_{i}^{D}$ is the demanded amount of a variety of the only consumption good.

For convenience, all goods produced under a regime of "warlord" or "stable political regime" production can be seen as varieties of one single good, where each of them gives an identical level of utility to the representative agent. ${ }^{5}$

As our locally non-satiated representative agent is at the same time the only producer and consumer in our competitive economy, and as all relative prices are positive, the aggregate demand for every variety of our commodity must equal its aggregate supply. Since we have only one agent, and by assumption initially no international trade takes place yet, we get:

$$
c_{i}^{D}=c_{i}^{S}
$$

where $c_{i}^{S}$ is the produced (and supplied) amount of commodity $i$.

As the utility function is strictly monotonic in all varieties of the consumption good, and the agent basically consumes what he produces, we can focus, in our analysis, exclusively on the production function of the goods. In order to maximize his utility, our agent simply maximizes production.

5 As opposed to the previous utility function, which referred to the choice between public and private goods, this one refers to the choice between fighting and producing and is thus labeled $u_{w f}$. The two utility functions are obviously linked, a fact that we will evoke below. 
Every variety $c_{i}^{S}$ has an identical production function, akin to the utility function 1.3 presented earlier:

$$
c_{i}^{S}=\exp \left(a-\frac{\theta}{w}-\frac{\pi}{q}\right)
$$

where $a=$ parameter, $w=$ part of time endowment allocated for producing, $q=$ part of time endowment allocated for fighting, $\theta=$ parameter expressing the gain of producing, $\pi=$ parameter expressing the gain of fighting.

This production function exhibits at first increasing then decreasing returns with respect to the arguments $p$ and $q$. This expresses the plausible assumption that initial increases in the levels of respectively fighting or producing activities will generate more than proportional returns in the production good $c_{i}^{s}$ but then eventually, with further increases of $p$ and $q$, less than proportional output will appear. If everything that is produced is consumed agent $i$ has simply the utility function $u_{i w f}=c_{i}^{S}$. This utility function is similar to the S-curve preference functions we introduced earlier. This production/utility function is subject to the constraint:

$$
(1-b) q+(1+k) w \leq 1-t+k \text { with } t>>b
$$

By definition, $w+q \leq 1$ since both variables represent parts of a total endowment. However, the initial commitment (analogous to a tax) for becoming a producer, which we call $k$, and $b$, the initial gain (analogous to a subsidy) of turning a producer into a fighter, will also affect the endowment as a whole. ${ }^{6}$ The "subsidy" to the fighter has to be usually more than compensated through a tax on the total endowment, $t$, which is assumed to be considerably $>b$. Similarly, the commitment taken by a producer, $k$, which is a net contribution to the total endowment, has to be accounted for. All these considerations are represented in the constraint (14). ${ }^{7}$

Thus, we assume that there are two ways of producing a particular good. Either the agent can choose the "stable political regime" production technique under which he has to make an initial commitment in order to get a higher return

6 The framework of the constraint is inspired by Dasgupta and Heal's (1979) similar reasoning for the case of public goods.

7 We can see from this budget constraint how we could overcome the restriction posed in Assumption 6 and make our model necessary and sufficient for the explanation of war lord activities: the war lord is the one who organizes the taxation of resources to distribute the initial subsidy to fighters. 
in the long-run or he can choose the "warlord" production technique, which refers to the low-technology capability of exploiting natural resources in areas controlled by the armed forces and gets an initial boost from the switch to fighting.

The terms $\theta$ and $\pi$ correspond to the elasticity of producing and fighting, or to put it differently, to the impact of a marginal change in the amount of production and fighting time on the output.

The link between the outputs of the two rival production techniques is summarized in equation (15). The decision taker is myopic and only takes the short- and medium-run into account. As he ignores the future externalities of over-exploitation, he has incentives to extract more than the social optimum of natural resources:

$$
\theta=\pi(1-\varphi)+x_{i} \text { where } \varphi=-y E+z
$$

where $x_{i}=$ ordinary production in case of producing, $z=$ short-run gain of overexploitation, $E$ =externality of the overuse of the natural resources (positive number), $y=$ extent up to which the externality can be internalized if the agent is a producer (number between 0 and 1).

It is a priori difficult to determine whether $\theta>\pi$ or $\pi>\theta$, as the latter, $\pi$, benefits in the short-run from the gains of the over-exploitation of natural resources $(z)$ and as the former $\theta$ implies regular production and efficiency gains from the better internalization of the externality. The short-run gains from overuse correspond to the increased quantity of natural resource exploitation, whereas the gains of better internalization of the natural resources correspond to a higher sale price (as less is produced) and to a more efficient exploitation of natural resources. We will first assume that the overuse of natural resources is quite an important factor and that accordingly $\theta$ is smaller than $\pi$.

We can see that if the representative agent chooses to be a producer rather than a fighter, a gain due to the internalization of the externality, $y E$, is possible, if an international cartel of the producers of the particular natural resource takes place or if the property rights are better protected than in the warlords-case. An international cartel fights the price depressing-effect and restricts the quantity (less overuse) to keep prices high. ${ }^{8} \mathrm{~A}$ good level of property rights protection assures a more efficient exploitation of natural resources.

In addition, as described by equation (17), a high level of property rights protection may also favor the "regular" production $x_{i}$.

8 Empirical cases of such international cartels include the OPEC or the coffee cartel until the 1990s. 
Equation (18) stresses furthermore that a society with a certain control of the quantity produced (due to the protected property rights) is more likely to form an international cartel with other similar societies.

Using (13) and (14), we get the following production maximization problem:

$$
\max _{w, q} \exp \left(a-\frac{\theta}{w}-\frac{\pi}{q}\right)
$$

subject to $(1-b) q+(1+k) w \leq 1-t+k$, and from (15) after transformation $\pi=\frac{\theta-y}{1-\varphi}$

This can be expressed by the following Lagrangian:

$$
L=\exp \left(a-\frac{\theta}{w}-\frac{\pi}{q}\right)+\lambda(1+k-t-(1-b) q-(1+k) w)+\mu\left(\pi-\frac{\theta-y}{1-\varphi}\right)
$$

Calculating the partial derivatives of $L$ with respect to $w, q, \lambda, \mu$ (the first-order conditions) gives us equation (18) after rearrangement:

$$
\frac{\pi}{q^{2}}=\frac{\theta}{\frac{(1+k-t-(1-b) q)^{2}}{(1+k)^{2}}}
$$

After rearranging (18), we can distinguish two possible equilibria (all other possibilities violate the restriction $0 \leq q \leq 1$ ), which we obtain by taking the square root on both sides. We get:

$$
q_{1}=\frac{1-t+k}{1-b+\sqrt{\frac{\theta}{\pi}}(1+k)}
$$

and

$$
q_{2}=\frac{1-t+k}{1-b+\sqrt{\frac{\theta}{\pi}}(1+k)}
$$

As expected, a higher $b$ and a higher $k$ result in a higher chosen level of fighting activity, since the first partial derivatives of (22) and (23) with respect to $b$ are:

$$
\frac{\partial q_{1}}{\partial b}=\frac{1+k-t}{\left(1-b+(k+1) \sqrt{\frac{\theta}{\pi}}\right)^{2}}
$$


and

$$
\frac{\partial q_{2}}{\partial b}=\frac{1+k-t}{\left(1-b+(k+1) \sqrt{\frac{\theta}{\pi}}\right)^{2}}
$$

These are always positive, provided $t<1+k$. In addition, it can also be shown that the first partial derivatives of $q_{1}$ and $q_{2}$ with respect to $k$ are positive. They are:

$$
\frac{\partial q_{1}}{\partial k}=\frac{1-b+t \sqrt{\frac{\theta}{\pi}}}{\left(1-b-(k+1) \sqrt{\frac{\theta}{\pi}}\right)^{2}}
$$

and

$$
\frac{\partial q_{2}}{\partial k}=\frac{1-b+t \sqrt{\frac{\theta}{\pi}}}{\left(1-b-(k+1) \sqrt{\frac{\theta}{\pi}}\right)^{2}}
$$

The equations (26) and (27) are always positive if $1 \geq b+t \sqrt{\frac{\theta}{\pi}}$.

Interesting consequences appear, when $\theta$ and $\pi$, the elasticities of producing and fighting, or to put it differently, the impact of a marginal change of the amount of production and fighting activity on the output, are considered.

In the case of the "good" equilibrium $q_{1}$ (where $q$ is low), an increase in $\theta$ decreases $q$ (the partial derivative of $q$ with respect to $\theta$ is always negative). This seems intuitive for a situation, where incentives work properly. By contrast, for the "bad" equilibrium $q_{2}$, the so-called "fighting warlords" trap, a greater value of $\theta$ actually increases $q$ (the partial derivative of $q$ with respect to $\theta$ is always positive). The equilibrium value $q_{2}$ is a "high" conflict outcome, where a great proportion of the population has an incentive to engage in fighting rather than producing through more conventional means. This means, that when fighting is generalized in our model, even an increase in the elasticity of traditional production will not only leave the situation unchanged but will push an even higher proportion of the population into fighting. The society in question is then caught in what can be called a "fighting warlords trap."

9 This particular finding is compatible with the point made by De Soysa et al. (1999) that there are high rates of civil wars in agrarian societies since production can here take any form. Notice that agricultural productivities are relatively low in agrarian societies. Moreover, these are often also producers of natural resources. 
However this process has a limit, which is given by the ratio $\frac{\theta}{\pi}$. If $\theta$ is $>\pi$, then the denominator of the fraction, which determines $q_{2}$ becomes negative and thus $q_{2}$ itself is negative, which contradicts our assumptions. Thus, if $\theta>\pi$ only the $q_{1}$ solution is possible. The ratio $\frac{\theta}{\pi}$ constitutes thus a bifurcation which establishes the possibility or not of such a "fighting warlords" trap. In other words, a massive increase in $\theta$ through a better internalization of the natural resource externality or a greater capacity to produce without fighting will make the "warlord trap" equilibrium impossible.

Thus, the higher the profits made with natural resources under a stable political system regime relative to those made under a system of competing warlords are, the less likely is the latter to occur.

Further, higher probabilities of an international cartel for the natural resource, $P m$, and of an operating property rights protection and rule of law system, $P p$, increase the likelihood of a stable political system outcome by increasing $x_{i}$ and $y$ in equation (15). On the other hand, higher immediate gains from fighting, $b$, and higher initial commitments for producing, $k$, increase both the risk of civil war.

If the immediate gains from natural resources, $b$, have a clearly negative impact on the democratization and the establishment of the rule of law, the impact of $\pi$ depends on the values of several other parameters. To deal with those, recall that equation (15) expresses $\theta$ in terms of $\pi$ :

This relation illustrates the idea that if the gains of the natural resource exploitation technology under a regime of warlordism, $\pi$, are bigger than the gains of production in a stable political system, $\theta$, it is because of the bigger quantity of natural resources exploited, due to overuse. This point is also made, as mentioned, in Chichilnisky (1994).

Clearly, these bigger gains from the warlordism exploitation technology are not sustainable in the long-run, because of the negative impact of over-exploitation. From an evolutionary point of view the gain from exploiting natural resources, $\pi$, should approach zero in the long-run.

It is interesting to see what the implications of extreme values of $\pi$ are on the level of $q$. If we replace $\theta$ by its value defined in relation (15) we get the following equations:

$$
q_{1}=\frac{1-t+k}{1-b+\sqrt{\frac{\pi(1-z+y E)+x_{i}}{\pi}}(1+k)}
$$




$$
q_{2}=\frac{1-t+k}{1-b+\sqrt{\frac{\pi(1-z+y E)+x_{i}}{\pi}}(1+k)}
$$

For a very small $q$, we would get in the square root, which is in the denominator of the above fractions, almost just the standard (as opposed to the resource) production, $x_{i}$, divided by a very small number, which would result in the value of the square root becoming increasingly large. We have thus:

$$
\lim _{\pi \rightarrow 0} q=0
$$

By contrast, as $\pi$ approaches infinity, $x_{i} / \pi$ becomes very small within the square root, which leaves:

$$
\lim _{\pi \rightarrow \infty} q=\frac{1-t+k}{(1-b) \pm \sqrt{(1-z+y E)}(1+k)}
$$

Thus, within the framework of the present model, a very low level of natural resources decreases the risk of a civil war outcome to close to zero, whereas for medium and high levels of natural resources we obtain higher levels of $q$. But the relationship between $\pi$ and $q$ is not monotonous. These implications are in accord with the empirical findings of Collier and Hoeffler (1998).

\section{Coalition behavior}

Our coalition type game is based upon the notion of "oceanic games," a concept introduced by Milnor and Shapley (published 1978 but elaborated earlier in a RAND paper) and then further developed by Straffin (1977). If a society is divided up into coalition kernels $N$ and $M$ (for instance two opposing factions) and a large number of uncommitted bystanders $U$, the coalition dynamic can result in bystanders joining either $N$ or $M$ based either on uncommitted evaluation of the probability of $N$ or $M$ overtaking the other faction (i.e., join the likely winner) or conversely on the fear that such a perspective might actually occur (defend the possible loser for fear of the likely winner). We thus rejoin the considerations made earlier about emotional aspects of mobilization for conflict. Once coalitions are established, mobilization of their respective strengths in numbers can occur, social distance between them will increase and then conflict and violent clashes 
can happen. These will be simulated with territorial and information issues introduced. ${ }^{10}$

Clearly, the coalition perspective, which can reiterate some aspects of the emotional factors in conflict, shows how confrontations can be influenced and enhanced by their own dynamics. In other words, conflict begets conflict as more and more individuals are drawn into it. This is in our view the main value added of the present approach: Whereas other conceptions stay at a relatively static level, our vision leads to an endogenous possible amplification (or for that matter reduction) of conflict.

In order to model how violence and conflict can break out, one can conceive of sets of potential coalitions of fighters whose numbers will grow as a result of the advantage of joining such a group as opposed to staying neutral or uncommitted.

Suppose we have group $n$ and group $m$ opposed to each other within the population of $N$ members. For group $n$ we can express this in the following way:

$$
\frac{\partial A(n)}{\partial n} \geq \frac{A(u)}{u}
$$

In other terms, it is worth joining a group of $n$ potential fighters if the advantages $A(n)$ where $n$ represents the number of fighters within group $N$ are greater than those $A(u)$ of remaining uncommitted $(u)$. The advantages of remaining uncommitted tend to diminish as the total number of fighters increase. This notion should not mean that joining a coalition is necessarily voluntary. Our formulation reflects among other things the fact that uncommitted members of society can be coerced into fighting the more fighters there are so that staying uncommitted gets to be extremely costly. So if we assume that the advantages of joining increase logarithmically with an expansion in the number of a group's committed fighters and that the advantages of staying within the uncommitted group $u$ diminish linearly with the percentage of fighters in the society $q$. So that we have then:

$$
\frac{\partial \chi \ln (n)}{\partial n}=\frac{A-(q N)}{N-(n+m)}
$$

10 Clearly our intention is to go farther here than conceptions based solely upon micro-level analyses such as the ones by Kalyvas (2006) and Kalyvas and Kocher (2009). While the conceptual importance of the territorial approach pioneered by him is fully acknowledged, it begs the question of the origins and developments of armed groups and their recruitment dynamics which cannot be uniquely based upon the provisions of collective and private goods and coercion at least in the beginning of a conflict. Incentives to fight based upon general economic conditions certainly have a place in the analysis as we are trying to suggest here. 
and thus $n$ :

$$
n=\frac{\chi(N-m)}{A-q N+\chi}
$$

Similarly we should have for $m$ :

$$
\frac{\partial \xi \ln (m)}{\partial m}=\frac{B-(q N)}{N-(n+m)}
$$

and finally $m$ is:

$$
m=\frac{\xi N(A-q N)}{(B-q N)(A-q N+\chi)+\xi(A-q N)} p
$$

These give us values for evolving $n_{s}$ and $m_{s}$.

Here $\chi$ and $\xi$ are adjustment parameters which can be interpreted as the evolving inverses of the probabilities of success of one or the other coalition (so these parameters can vary over time). Such parameters can help taking into consideration events that are not covered within the framework of the model such as the international context: For instance, the beginning of what has been called the Arab spring had an influence which extended way beyond the borders of Tunisia and Egypt. It showed to other populations of the Middle Eastern region that regime change was possible. This hikes the probability of an uprising to be successful and lowers the probability of the existing regime to stay in power. This does not mean however that the regime will then necessarily crumble. $A$ and $B$ are parameters representing the initial advantages of staying uncommitted with respect to either $n$ or $m$.

\section{Combat model}

Combat equations can now be written in the following way if one assumes that $n$ corresponds to insurgents and $m$ to the dominant group:

$$
\begin{gathered}
\frac{d c o m b n}{d t}=\operatorname{par} 10(\operatorname{par} 1 n-\text { par2 combncombm }) \\
\frac{d c o m b m}{d t}=\operatorname{par} 10(-\operatorname{par} 3 n+\operatorname{par} 4 \mathrm{~m}) \\
\frac{d t a r n}{d t}=\operatorname{par} 5 n-\operatorname{par} 6 \operatorname{par} 7 \mathrm{~nm}
\end{gathered}
$$




$$
\begin{aligned}
\operatorname{par} 6= & 1 \text { if }(\text { par } 8 \text { combm }- \text { combn })<0 \\
& 0 \text { otherwise }
\end{aligned}
$$

$$
\begin{gathered}
\text { survn }=n-\text { tarn } \\
\text { par10 }=1 \text { if } q_{1} \text { and } q_{2}>q^{\star} \\
0 \text { otherwise }
\end{gathered}
$$

(34) is a Deitchman-Lanchester (Deitchman 1962) equation describing dispersed combat with replacement. This corresponds to a situation where a dominant group blankets an area to hit insurgents. combn and combm are variables representing combatants of $n$ and $m$ respectively. Their evolution is described in (34) and (35) as combats develop as functions of kill probabilities and of replacements from the larger groups $n$ and $m$. In dispersed combat, losses depend on chance encounters (product) of combatants, par2 is a parameter expressing kill likelihoods in a encounter; par1 represents a replacement parameter where a fraction of $n$ replaces $n$ 's losses. (35) is a Lanchester concentration equation since insurgents can target dominant combatant groups in a concentrated way through ambushes. Here par3 and par4 represent respectively a kill likelihood and a replacement rate. (36) Expresses the notion that an insurgent group can be targeted (tarn) through intimidation and massacres that will affect its total population directly (without the intermediary of combat). This situation is now extant in Syria for instance. The survivor population (survn) defined in (38) will account for the effects of this massacre strategy. Relation (37) represents conditions under which massacres and intimidations will occur: essentially when one group of combatants is numerically strong enough to threaten seriously the domination of the more powerful group. Fear of a strong change in the balance of power should then trigger massacres. The parameter par6 indicates that this will occur when the combatants of the insurgent group reaches a certain size determined by par8: For instance if group $n$ combatants reach parity or superiority over group $m$ fighters. Finally in (39) par10 represents a logical switch which specifies that fighting will only start whenever the fighting propensities $q_{1}$ and $q_{2}$ are greater than a minimal threshold level $q^{\star}$. In other words, if the intensity to fight is low enough in a society, no combats will actually take place.

Clearly, the coalition perspective, which can reiterate some aspects of the emotional factors in conflict, shows how confrontations can be influenced and enhanced by their own dynamics. In other words, conflict begets conflict as more and more individuals are drawn into it. This is in our view the main value added of the present approach: Whereas other conceptions stay at a relatively static 


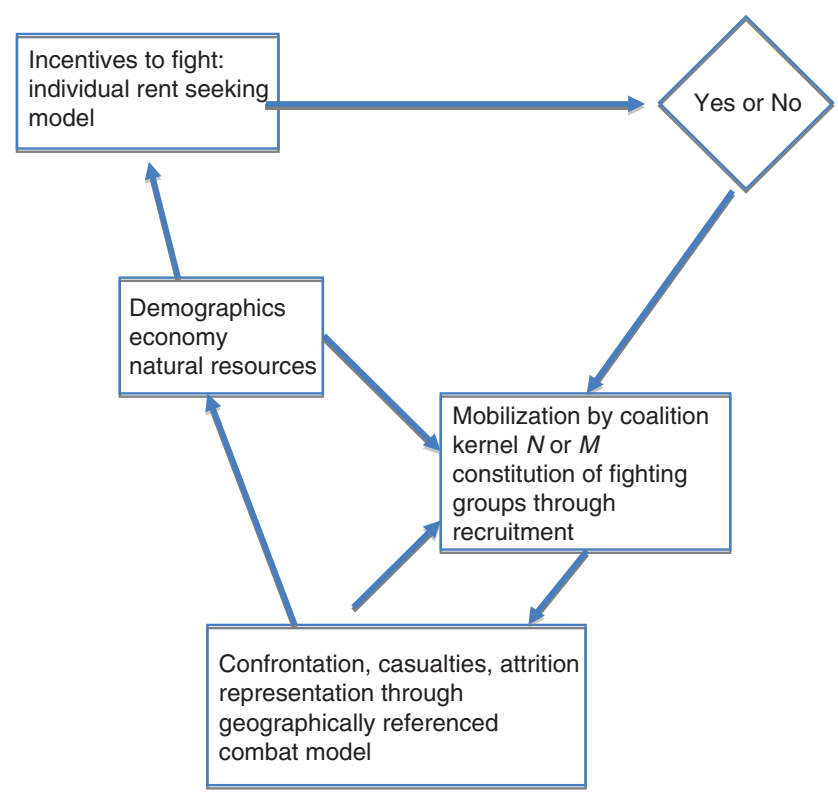

Figure 4: Schematic Representation of our Agent Based Model.

level, our vision leads to an endogenous possible amplification (or for that matter reduction) of conflict.

This model can lead to conflict escalation and stable societal conflict traps. On the other hand, we show also that such situations are basically inefficient and that in fact any unequal situation within society that is not compensated by transfers from the more powerful or wealthier to poorer segments of society is inefficient. This particular result illustrates the neuroscience finding that increased inequality in a social hierarchy favors conflict. To show how the conflict dynamics can work in our framework, we will use the following Figure 4:

Some of these conclusions will be illustrated below with the help of our simulation model.

\section{Simulation model construction}

The relations presented above can now be coded in a simulation model, which is for the moment written in the context of the SPARE system developed at the Graduate Institute. This system allows us to write directly dynamic relations and recursive algebraic equations. Once the model is formulated different scenarios 
suggested by the mathematical analysis done above can be investigated. In particular, the kind of coalition behavior, which can amplify conflict behavior, can be analyzed in this way. The simulation model is subdivided into basic economic relations, fighting incentive relations, coalition behavior and combat equations. In principle the model can be regionalized to various geographical entities depending on the availability of data such as macroeconomic and demographic variables at the regional and sub-regional levels. Here is the transcription of the model script:

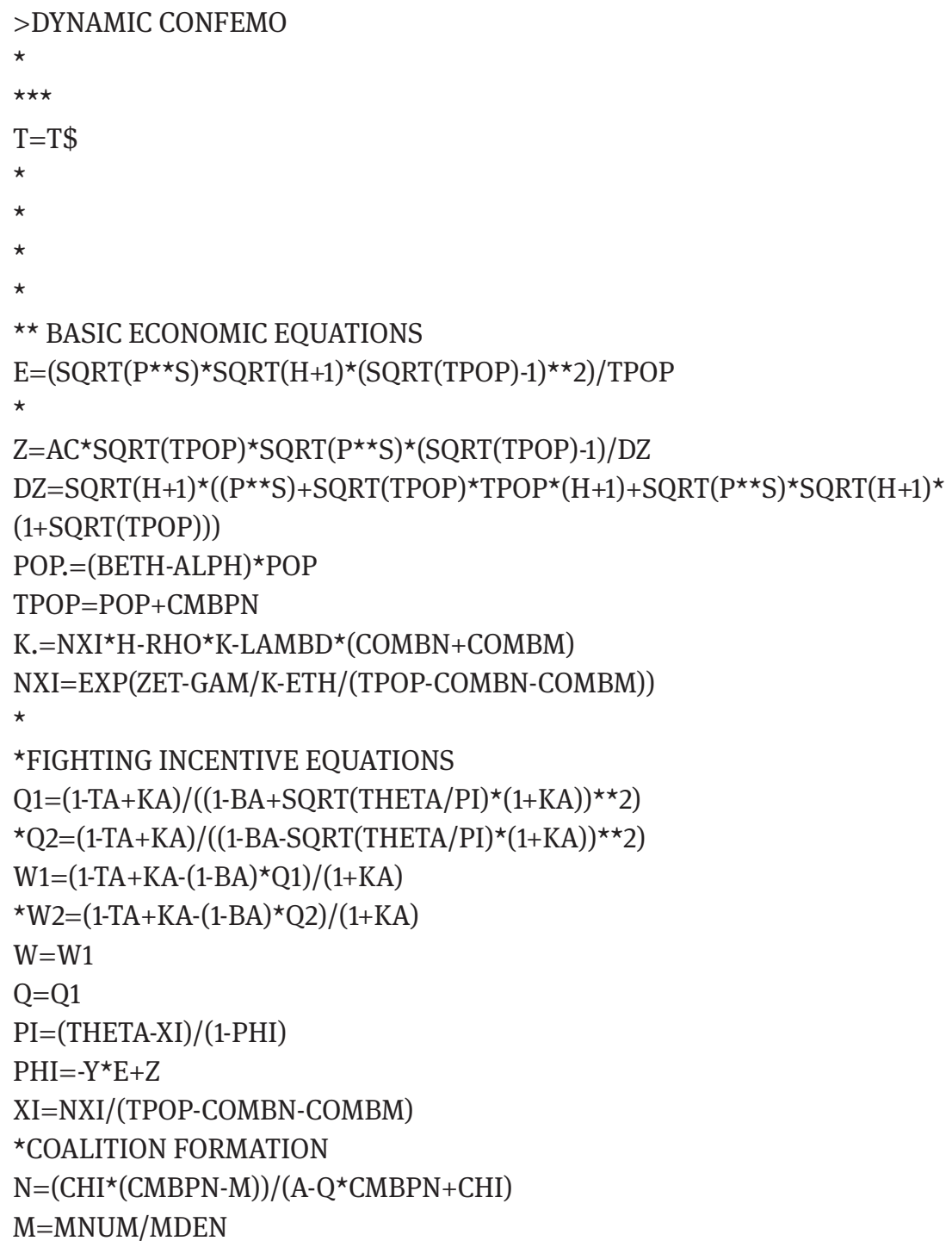




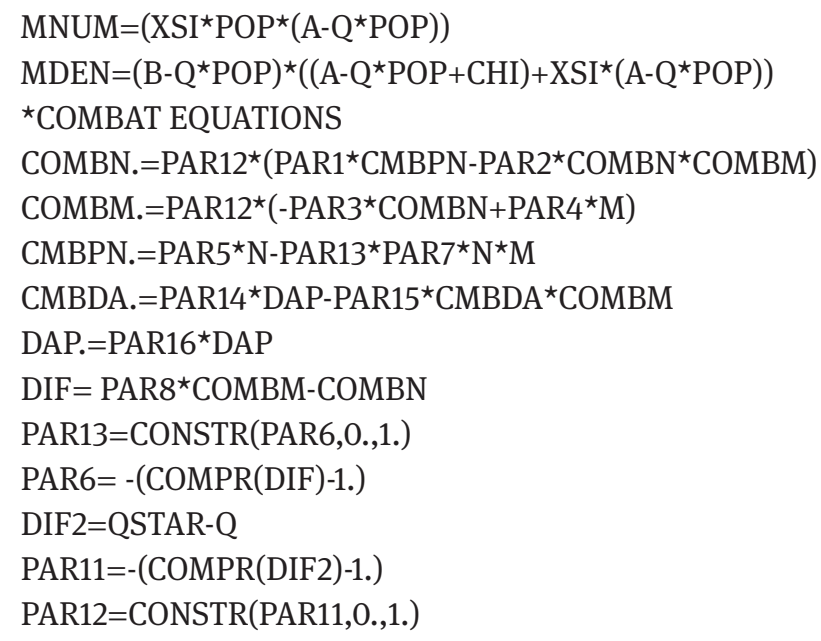

\section{Simulation scenarios}

We will start exploring the possibilities of the model by using a pure simulation scenario with little relations to the empirical world. Rough calibrations have been carried out in order to account for the basic demographic and macroeconomic variables of Sudan to just take one practical example. However, at this stage as mentioned before no analogy should be drawn to a real situation. The scenarios are just there to show what drives the model.

What we see here in the above figure (Figure 5) is an increasing level of GDP for a country whose macroeconomic and demographic characteristics are like those of Sudan. Because of that (according to the model) things turn out well.

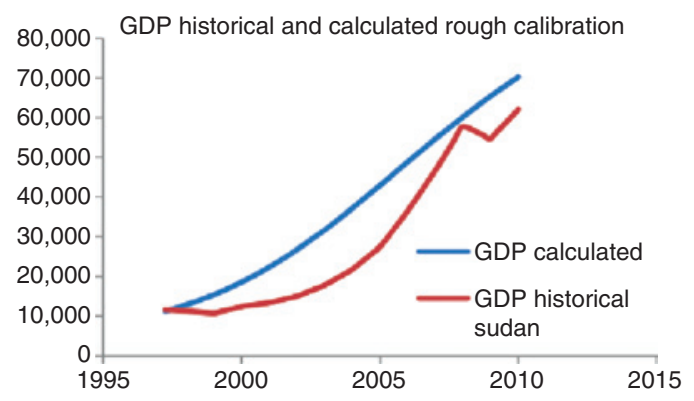

Figure 5: Calculated and Historical Values for Simulation Scenario: GDP. 
Enough resources are shared in such a way that the $\mathrm{N}$ coalition (in our conception the insurgent group) after rising initially declines (Figure 6).

But so does the dominant group coalition which loses strength as seen in Figure 7:

This diminishes the propensity to fight as shown in Figure 8.

Finally the number of combattants for $\mathrm{N}$ rises quite slowly but then stops growing as $q$ diminishes enough to be below the combat threshold $q^{\star}$ as shown in Figure 9:

We can now contrast this with an Economic Collapse Scenario that is represented in Figure 10:

In the economic collapse scenario capital growth slows down significantly which rsults in a significant lowering of GDP. The propensity to fight increases until leveling of at a high level plateau as shown in Figure 11:

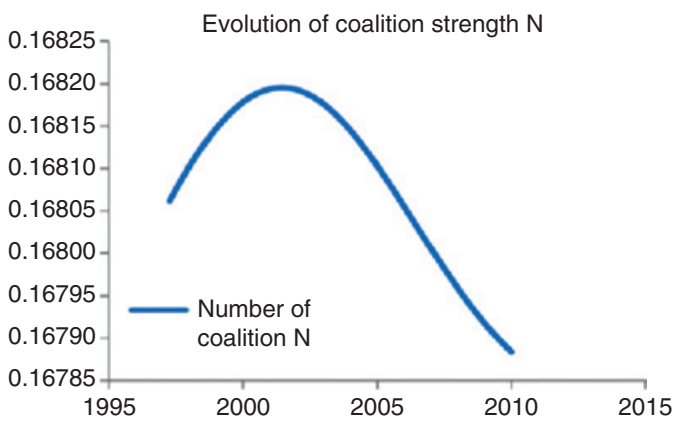

Figure 6: Simulation of Coalition Strength of Regime Opponents.

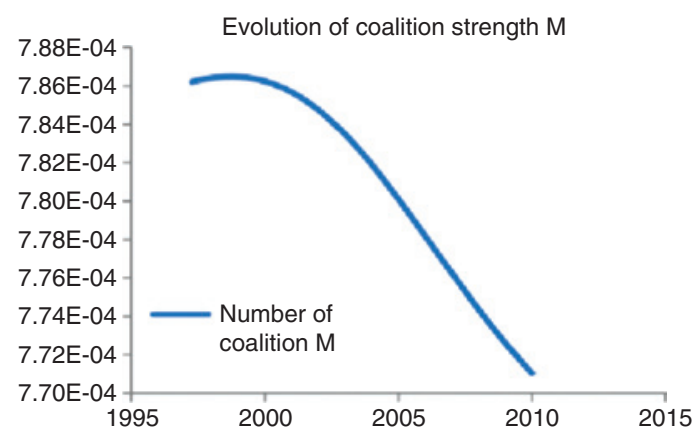

Figure 7: Simulated Values of Pro-Regime Coalition. 


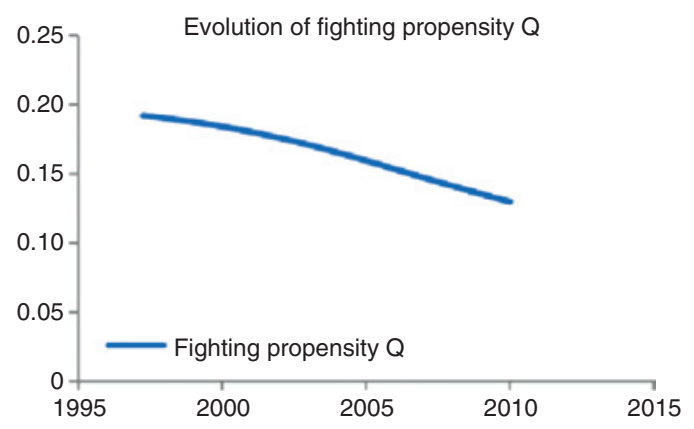

Figure 8: Evolution of Simulated Fighting Propensity within the Society.

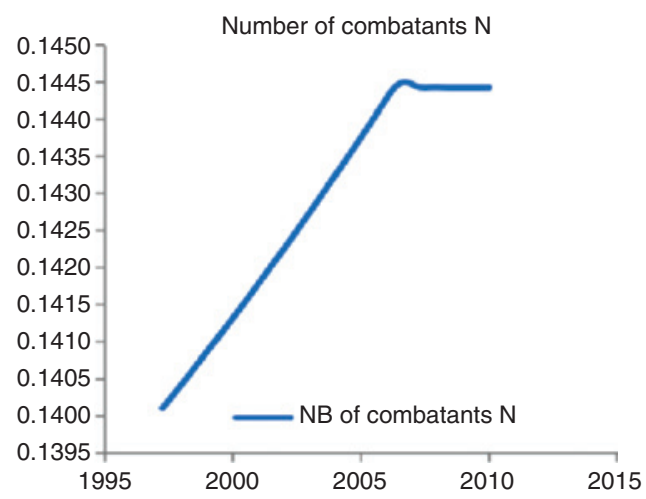

Figure 9: Evolution of Simulated Number of Rebel Combatants.

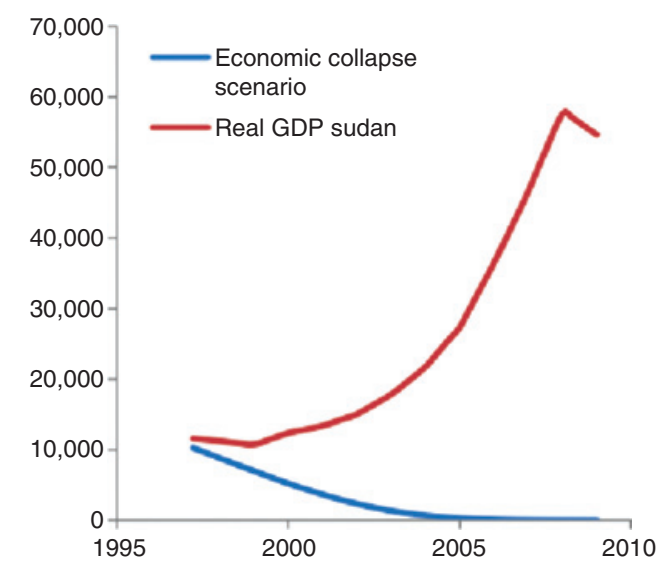

Figure 10: Evolution of GDP under a Simulated Economic Collapse Scenario. 


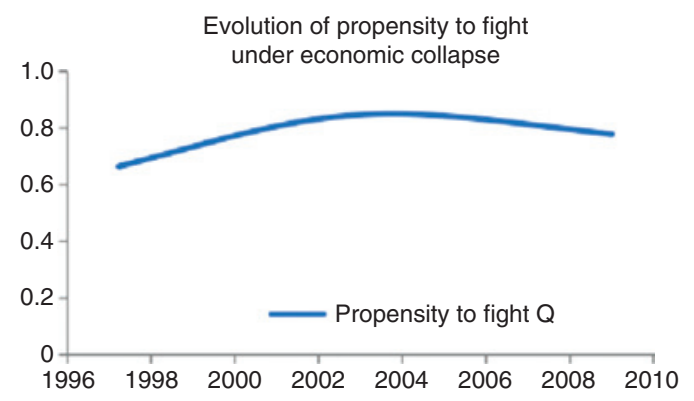

Figure 11: Evolution of Simulated Propensity to Fight under Economic Collapse Scenario.

The coalitions of both $\mathrm{N}$ and $\mathrm{M}$ increase in numbers as shown in Figures 12 and 13 adding to the conflict escalation:

As a result, the number of fighters for $\mathrm{N}$ increases with associated combat damages on the armed forces of M (Figure 14).

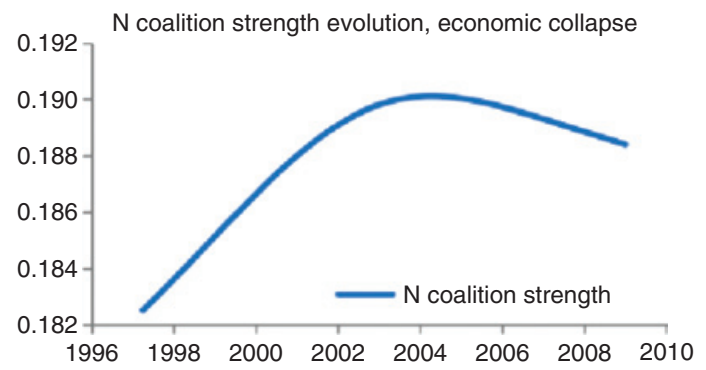

Figure 12: Evolution of Simulated Anti-Regime Coalition Strength under Economic Collapse Scenario.

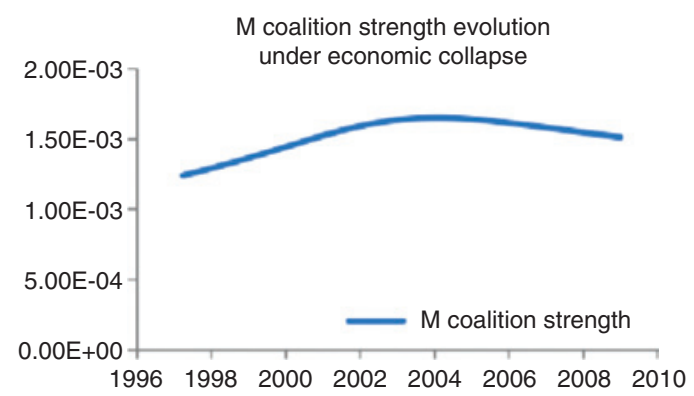

Figure 13: Evolution of Simulated Pro-Regime Coalition Strength under Economic Collapse Scenario. 


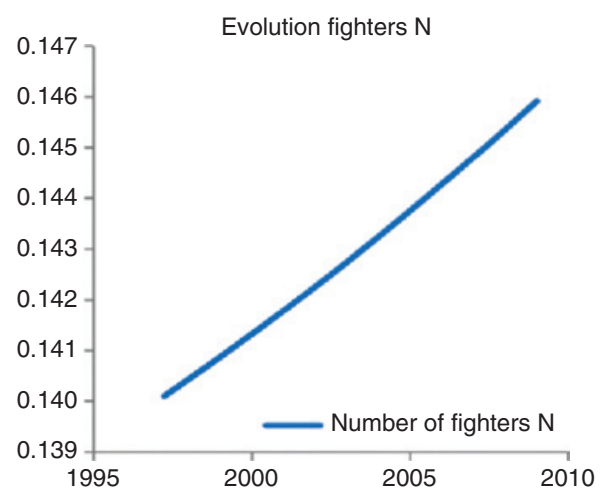

Figure 14: Evolution of Number of Anti-Regime Fighters under Economic Collapse Scenario.

\section{Beyond pure simulations: the case of Syria}

Syria has witnessed since 2011 an intensive civil war which has already resulted in aprroximately 160,000 deaths. It is harder to evaluate the number of casualties which must be much higher than that. The government of Bashar El Assad which relies very much on the Alaouite (roughly speaking a branch of Chiism) sect of Islam faces an uprising that envompasses mostly Suni Moslems but also Kurds, the two forces not cooperating necessarily always against him. This uprising has attracted some elements of the Syrian army but also islamist groups which makes it difficult for the anti Assad coalition to stick together. After some initial successes by the anti-governement forces one seems to presently face a stalemate with a war of attrition going between both sides. How does our model do in this case? A priory, it seems hard to explain anything via some kind economic collapse as sugggested by our simulation scenario because economic data show upward trends in the years before the uprising. But then Syrian data are notoriously unreliable and show some developments that cannot possibly be correct given the toll that the civil war inflicts upon the country, such as an increase in GDP in 2011. Earlier data show a marked slump in the beginning of the 2000s and it is likely that this slump continued with a slight attenuation through the end of the decade. Even with these unreliable informations our model reproduces the historical development rather well. For instance, population and GDP figures are well predicted by it as these two graphs of population calculated and observed and GDP calculated and observed ${ }^{11}$ for Syria reveal (Figures 15 and 16):

11 Our parameters are a priori evaluations and not statistical estimations, thus the use of correlation coefficients rather than other statistics. 


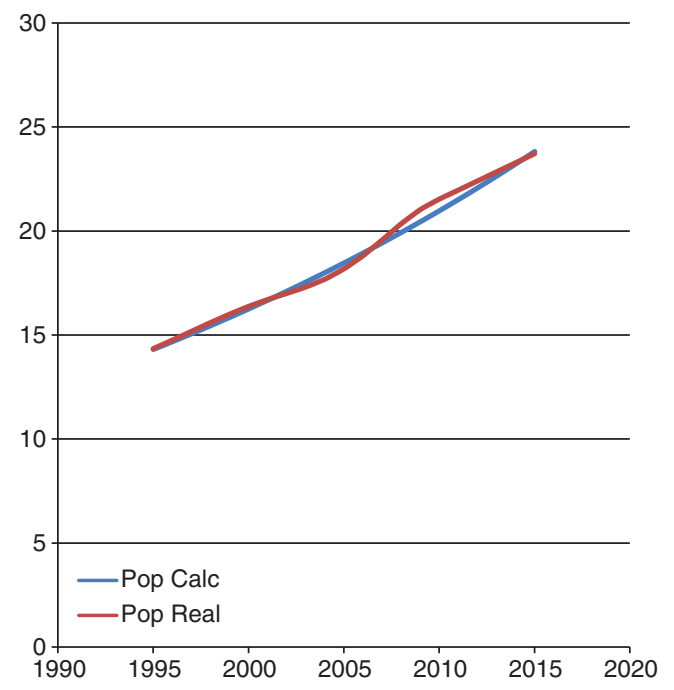

Figure 15: Calculated and Observed Population Evolutions for Syria 1990-2015. Source: Penn World Tables, Feenstra et al. 2013. $(R=0.9966, p<0.00001)$.

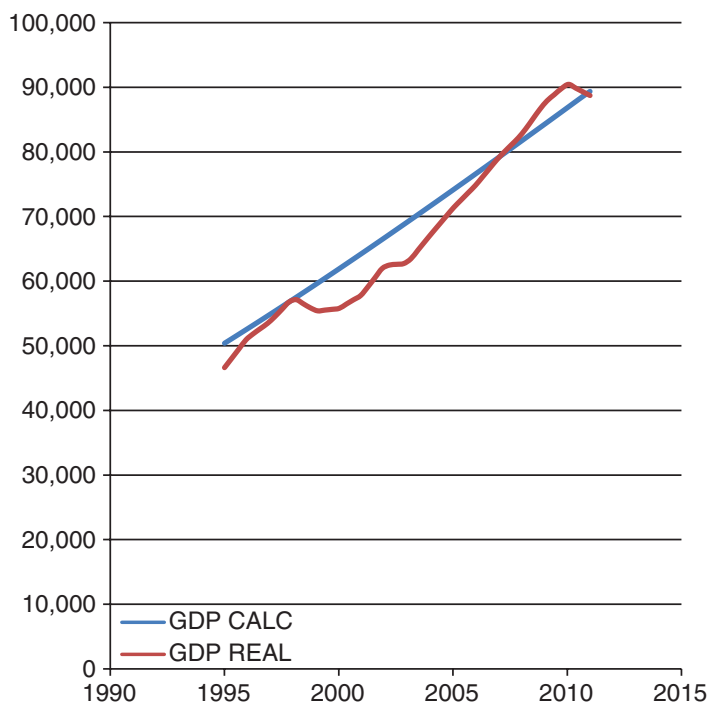

Figure 16: Syria: GDP Real and Calculated 1995-2011. Source: Penn World Tables, Feenstra et al. 2013. $(R=0.982, p<0.00001)$. 
In order to deal with the problems posed by the underestimations of the difficulties of the economic context in Syria, we relied heavily on another indicator of the uncertainty associated with the Syrian regime. This indicator was constructed by Thierry Lorho (Lorho et al. 2014). His approach is based upon an analysis of textual data about Syria, available mostly over the Internet, in the form of big quantities of machine-readable documents. The textual material is analyzed via a Bayesian algorithm called D-Bacl, which looks at the concatenation of various words and concepts in a text. These are then evaluated statistically according to their probabilities of occurrence and the relationships that link them to each other. In this way the information content of each word and sequence of words can be assessed based upon Shannon's information theory. Based upon this methodology, an uncertainty indicator for the Syrian regime is extracted from this information. As can be seen form the graph below, this indicator seems to capture well the evolution of the likelihood of regime collapse in the country. This likelihood reaches a maximum at the end of 2011-beginning of 2012 but then declines markedly. One can observe that the indicator predicts with a slight lag the evolution of total casualties for the Syrian civil war which give it high plausibility. These peak in early 2013 and then decline also significantly. This can be seen in the following graph (Figure 17):

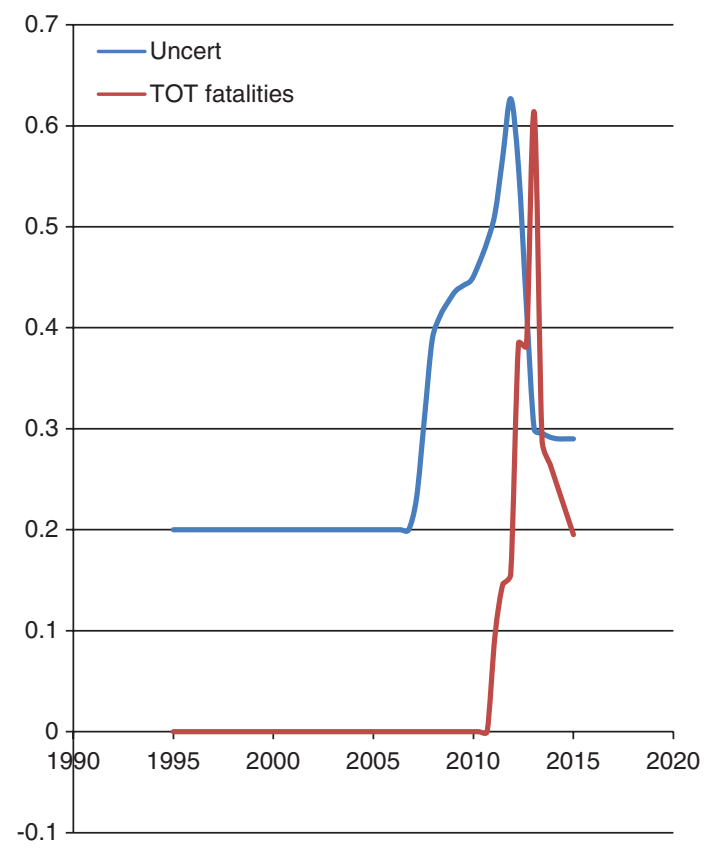

Figure 17: Uncertainty of Regime and Total Fatality Curves Syria.

Source: Syria and Lebanon Blogspot http://ncfsyria.blogspot.ch/, Breakdown of monthly casualty figures for Syria. 


\section{Evolution of regime uncertainty and total civil war fatalities, Syria 2007-2015}

We can now plug this indicator into our model. Its influence on the dynamics of our system is operating in two ways: First, through the evolving parameters $\chi$ and $\xi$ (the complement of $\chi$ ) that determine in part the changing coalition memberships of pro and anti-government forces as postulated in the relations (30) to (33). Parameter $\chi$ which is the probability of collapse of the governmental regime is thus expressed by the uncertainty indicator. Second, the uncertainty index also influences the propensity to fight. The assumption being here that a high governmental uncertainty value increases the incentives to fight the authorities. The model reflects well such an evolution in the membership of the government and insurgent coalitions. So as the government coalition first weakens in the years preceding the civil war and then during the beginning of it, it tends to strengthen again later from 2013 on to regain and even overcome its previous strength as illustrated by the graph below (Figure 18):

On the other hand, the insurgent coalition after rising in numbers from 2007 on reaches a peak in 2011 and then seems to decline afterwards. In terms of future developments the fate of this coalition appears to be bleak. This is illustrated by the following graph (Figure 19):

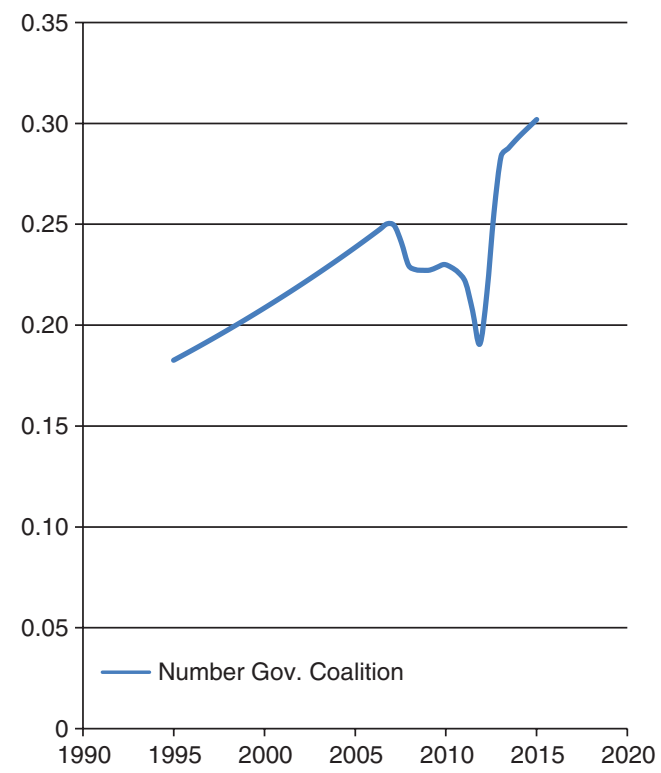

Figure 18: Syria: Evolution over Time of Government Backing Coalition. 


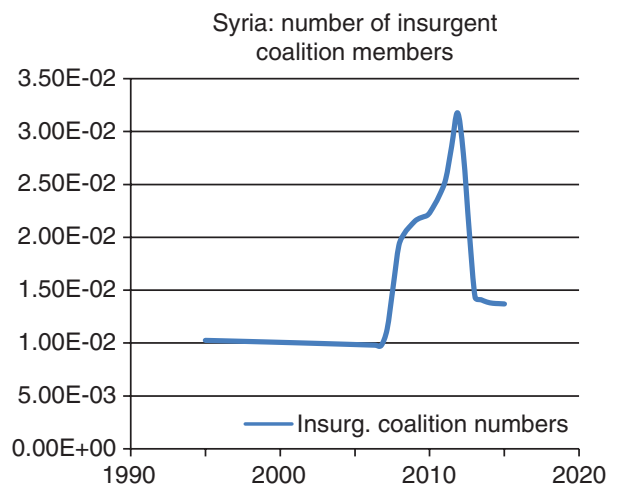

Figure 19: Evolution over Time of Insurgent Coalition.

We can then also from these and from the propensity to fight variables postdict quite well to combattant total casualties (Figure 20):

So, overall, our model accounts in a satisfactory way for the evolution of the Syrian Civil War. This shows that our conception is not only able to generate plausible hypothetical scenarios but also to represent empirical situations rather well. This opens new alleys for the study of the evolution of conflict in general and internal conflict in particular.

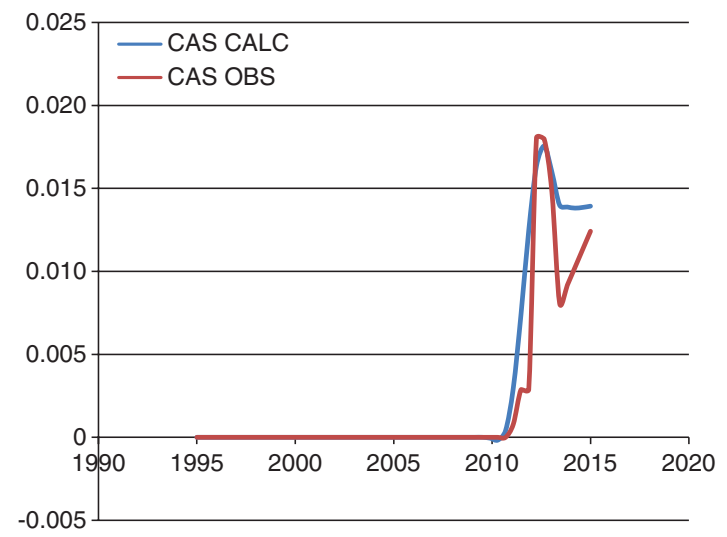

Figure 20: Syria: Observed and Calculated Combatant Casualties 2011-2014 $(R=0.8599$, $\mathrm{p}=0.000687$ ).

Source: Syria and Lebanon Blogspot http://ncfsyria.blogspot.ch/Breakdown of Monthly Casualty Figures for Syria. 


\section{Conclusions}

Quite clearly, if one follows the scenarios presented above, economic conditions drive the model since in one case sustained growth produces stability and end of combats whereas deteriorating capital growth and GDP collapse lead to increased hostile coalition participation and more fighting. However, things are not that simple since the mere trigger of economic conditions is insufficient to explain conflict escalation, which results from increased participation in mutually hostile coalitions and greater fighting propensity where emotions such as fear and resentment play their role. Without the postulated risk attitudes which translate these emotional aspects into mathematical and simulation language formulae the scenarios described above would not be conceivable. In some sense what our scenario analyses show so far is that external rewards (here the additional wealth derived from substantive growth rates) evoked by the neuro-science research play their role in attenuating conflict over time. It is remarkable to point out here to make an analogy to the Sudan situation, that the conflict between North and South essentially broke out initially as poor growth conditions prevailed but as these improved remarkably over the last decade, the situation essentially got better in terms of the hostilities and the compromise of separating the North from the South was made possible. Since we are again witnessing a deterioration of these conditions especially in South Sudan, it is not surprising that now this new country in in turn torn apart by a civil war.

The Syrian situation which constitutes here our main empirical example is interesting in the sense that here economic conditions alone do not trigger a response in the form of a civil war. It is the perceived and observed greater instability (or uncertainty) of the political institutions, which create the conditions for the civil war because these circumstances favor the perception that the regime is fundamentally weak and presents an opportunity for those who want to grab the power away from it. Moreover, the examples and diffusions of other Arab spring type movements certainly play a role here also. However, according to our indicator, this opportunity is short-lived and ultimately reveals the weakness of the insurgent coalition whose future looks increasingly bleak. This shows that conflict resolution schemes have also to take into account perceptions of opportunities as means to correct long-term grievances.

\section{References}

Allais, M., (1953), Le Comportement de l'homme rationnel devant le risque: Critique des postulats et axiomes de l'école américaine, Econometrica, vol. 21, no. 4, pp. 503-546. 
Arcand, Jean-Louis, Luterbacher, Urs, (2013), Conflict, the Harsanyi-Zeuthen Bargaining Solution, and Departures from Expected Utility, MS Graduate Institute of International and Development Studies.

Axelrod, R.M., (1980), The Evolution of Cooperation, Basic Books, New York.

Axelrod, R.M., (1986), An Evolutionary Approach to Norms, American Political Science Review, vol. 80, no. 4, pp. 1095-1111.

Axelrod, R., Hamilton, W.D., (1981), The Evolution of Cooperation, Science, vol. 211, no. 4489, pp. 1390-1396.

Baumgartner, T., Heinrichs, M., Vonlanthen, A., Fischbacher, U., Fehr, E., (2008), Oxytocin Shapes the Neural Circuitry of Trust and Trust Adaptation in Humans, Neuron, vol. 58, no. 4, pp. 639-650.

Bhavnani, R., Backer, D., (1999), Localized Ethnic Conflict and Genocide: Accounting for Differences in Rwanda and Burundi, Journal of Conflict Resolution, vol. 44, no. 3, pp. 283-306.

Bhavnani, R., Miodownik, D., Choi, H., (2011), Violence and Control in Civil Conflict: Israel, the West Bank, and Gaza, Comparative Politics, vol. 44, no. 1, pp. 61-80.

Cederman, L.E., (2003), Modeling the Size of Wars: From Billiard Balls to Sandpiles, American Political Science Review, vol. 97, no. 1, pp. 135-150.

Cederman, L.E., (2005), Computational Models of Social Forms: Advancing Generative Macro Theory, American Journal of Sociology, vol. 110, no. 4, pp. 864-893.

Chateauneuf, A., Cohen, M., Meilijson, I., (2005), More Pessimism than Greediness: A Characterization of Monotone Risk Aversion, Economic Theory, vol. 25, no. 3, pp. 649-667.

Chichilnisky, G., (1994), North-South Trade and the Global Environment, The American Economic Review, vol. 84, no. 4, pp. 851-874.

Chichilnisky, G., (2009a), Catastrophic Risks, International Journal of Green Economics, vol. 3, no. 2 , pp. 130-141.

Chichilnisky, G., (2009b), The Topology of Fear, Journal of Mathematical Economics, vol. 45, no. 12 , pp. 807-812.

Chichilnisky, G., Heal, G., Starrett, D., (2000), Equity and Efficiency in Environmental Markets: Global Trade in Carbon Dioxide Emissions, in Chichilnisky G., Heal, G., (eds.), Environmental Markets Equity and Efficiency, Columbia University Press, NY, pp. 46-67.

Collier, P., Hoeffler, A., (1998), On Economic Causes of Civil War, Oxford Economic Papers, vol. 50, no. 4, pp. 563-573.

Collier, P., Hoeffler, A., (2000), Greed and grievance in civil war, World Bank Policy Research Paper 2355, World Bank, Washington, DC.

Collins, R., (2008), Violence: A Micro-sociological Theory, Princeton University Press, Princeton, N).

Cordero M.I., Sandi, C., (2007), Stress Amplifies Memory for Social Hierarchy, Frontiers in Neuroscience, vol. 1, no. 1, pp. 175-184.

Deitchman S.J., (1962), A Lanchester Model of Guerrilla Warfare, Operations Research, vol. 10, no. 6, pp. 818-827.

De Soysa, Indra, Gleditsch, Nils Petter, Gibson, Michael, Sollenberg, Margareta (1999), To Cultivate Peace: Agriculture in a World of Conflict, Environmental Change and Security Project Report, no. 5, The Woodrow Wilson Center, Washington D.C.

Dugatkin, L.A., (2002), Animal Cooperation Among Unrelated Individuals. Naturwissenschaften, vol. 89, no. 12, pp. 533-541. 
Fearon, J., (1994), Signaling versus the Balance of Power and Interests: An Empirical Test of a Crisis Bargaining Model, Journal of Conflict Resolution, vol. 38, no. 2, pp. 236-269.

Fearon, J., Laitin, D., (1996), Explaining interethnic cooperation, American Political Science Review, vol. 90, no. 4, pp. 715-735.

Fehr, E., Camerer, C., (2007), Social neuroeconomics: the neural circuitry of social preferences, TRENDS in Cognitive Sciences, vol. 11, no. 10, pp. 419-427.

Feenstra, Robert C., Inklaar, Robert, Timmer, Marcel P., (2013), The Next Generation of the Penn World Table, NBER Working Paper, no. 19255, Nod in July 2013. Available for download at www.ggdc.net/pwt.

Friedman, M., Savage, L.P., (1948), The Utility Analysis of Choices involving Risk, Journal of Political Economy, vol. 56, no. 1, pp. 279-304.

Gardner Jr. R., Wilson, D.R., (2004), Sociophysiology and Evolutionary Aspects of Psychiatry, in Panksepp J., (ed.), Textbook of Biological Psychiatry, Wiley, Hoboken, NJ, pp. 597-625.

Gilbert, P., (2001), Evolutionary Approaches to Psychopathology: The Role of Natural Defenses, Australian \& New Zealand Journal of Psychiatry, vol. 35, no. 1, pp. 17-27.

Hamilton, I.M., Taborsky, M., (2005), Contingent Movement and Cooperation Evolve Under Generalized Reciprocity, Proceedings of the Royal Society of London, Series B, vol. 272, pp. 2259-2267.

Hofer, M.A., (1995), An Evolutionary Perspective on Anxiety, in Roose, S.P., Glick, R.A., (eds.), Anxiety as Symptom and Signal, Analytic Press, Hillsdale, NJ.

Homer-Dixon, T., (1994), Environmental Scarcities and Violent Conflict: Evidence from cases, International Security, vol. 19, no. 1, pp. 5-40.

Kahneman, D., Tversky, A., (1979), Prospect Theory: An Analysis of Decisions under Risk. Econometrica, vol. 47, no. 2, pp. 263-291.

Kalyvas, S.N., (2006), The Logic of Violence in Civil War, Cambridge University Press, Cambridge.

Kalyvas, S.N., Kocher, M.A., (2009), The Dynamics of Violence in Vietnam: An Analysis of the Hamlet Evaluation System, Journal of Peace Research, vol. 46, no. 3, pp. 335-355.

Kosfeld, M., Heinrichs, M., Zak, P.J., Fischbacher, U., Fehr, E., (2005), Oxytocin Increases Trust in Humans, Nature vol. 435, pp. 673-676.

Lohmann, S., (1993), A Signaling Model of Informative and Manipulative Political Action, American Political Science Review, vol. 87, no. 2, pp. 319-33.

Lorho T., Fert, V., Luterbacher, U., (2014), Predicting Political and Economic Crises with the Help of Textual Analysis of Large Sources: The Globe Expert Methodology, The Graduate Institute of International and Development Studies. Forthcoming.

Luterbacher, U., Norrlof, C., (2008), Securing the Environment and Securing States, in Chatterji, M., Fontanel, J., (eds.), Contributions to Conflict Management, Peace Economics, and Development, vol. 6, War, Peace and Security, Emerald Group Publishing Limited, pp. 267-297.

Luterbacher, U., Krasna, B., (2010), Towards understanding conflict elicitation and conflict resolution: challenges for brain, behavioral and social sciences, in Moira Cockell et al. edit. Common Knowledge: The Challenge of Transdisciplinarity EPFL Press Lausanne, forthcoming.

Mendres, K.A., de Waal, F.B.M., (2000), Capuchins do Cooperate: The Advantage of an Intuitive Task, Animal Behaviour, vol. 60, no. 4, pp. 523-529. 
Meyer-Lindenberg, A., (2008), Impact of Prosocial Neuropeptides on Human Brain Function, Progress in Brain Research, vol. 170, pp. 463-470.

Milnor, J.W., Shapley L.S., (1978), Values of Large Games, II: Oceanic Games, Mathematics of Operations Research, vol. 3, no. 4, pp. 290-307.

Nesse, R.M., (1999), Proximate and Evolutionary Studies of Anxiety, Stress and Depression: Synergy at the Interface, Neuroscience \& Biobehavioral Reviews, vol. 23, no. 4, pp. 899-912.

von Neumann, J., Morgenstern, O., (1947), Theory of Games and Economic Behavior, Princeton University Press, Princeton.

Nowak, M.A., Sigmund, K., (1998a), The Dynamics of Indirect Reciprocity, Journal of Theoretical Biology, vol. 194, no. 4, pp. 561-574.

Nowak, M.A., Sigmund, K., (1998b), Evolution of Indirect Reciprocity by Image Scoring, Nature, vol. 393, pp. 573-577.

Nowak, M.A., Sigmund, K., (2005), Evolution of Indirect Reciprocity, Nature, vol. 437, pp. 1291-1298.

Nowak, M.A., Roch, S., (2007), Upstream reciprocity and the evolution of gratitude, Proceedings of the Royal Society of London, Series B, vol. 274, pp. 605-610.

O’Neill, B., (1986), International Escalation and the Dollar Auction, The Journal of Conflict Resolution, vol. 30, no. 1, pp. 33-50.

Panksepp, J., (2005), Affective Consciousness: Core Emotional Feelings in Animals and Humans, Consciousness and Cognition, vol. 14, no. 1, pp. 30-80.

Panksepp, J., (2006), Emotional Endophenotypes in Evolutionary Psychiatry, Progress in NeuroPsychopharmacology \& Biological Psychiatry, vol. 30, pp. 774-784.

Pfeiffer T., Rutte, C., Killingback, T., Taborsky, M., Bonhoeffer, S., (2005), Evolution of Cooperation Through Generalized Reciprocity, Proceedings of the Royal Society of London, Series B, vol. 272, pp. 1115-1120.

Rutte, C., Taborsky, M., (2007), Generalized Reciprocity in Rats, Plos Biology, vol. 5, no 7, pp. 1421-1425.

Rutte C., Taborsky, M., (2008), The Influence of Social Experience on Cooperative Behavior of Rats (Rattus norvegicus): Direct vs Generalized Reciprocity, Behavioural Ecology \& Sociobiology, vol. 62, no. 4, pp. 499-505.

Shubik, M., (1971), The Dollar Auction Game: A Paradox in Noncooperative Behavior and Escalation. The Journal of Conflict Resolution, vol. 15, no. 1, pp. 109-111.

Singer, T., Kiebel, S.J., Winston, J.S., Dolan, R.J., Frith, C.D., (2004), Brain Responses to the Acquired Moral Status of Faces, Neuron, vol. 41, pp. 653-662.

Straffin Philip D. Jr., (1977), The Bandwagon Curve, American Journal of Political Science, vol. 21, no. 4, pp. 695-709.

Timmer, M., Cordero, M.I., Sevelinges, Y., Sandi, C., (2011), Evidence for a Role of Oxytocin Receptors in the Long-Term Establishment of Dominance Hierarchies, Neuropsychopharmacology, vol. 36, pp. 2349-2356.

Trivers, R., (1971), The Evolution of Reciprocal Altruism, The Quarterly Review of Biology, vol. 46, no. 1, pp. 35-57.

Uvnas-Moberg, K., (1998), Oxytocin May Mediate the Benefits of Positive Social Interaction and Emotions. Psychoneuroendocrinology, vol. 23, no. 8, pp. 819-835.

Zak, P.J., Kurzban, R., Matzner, W.T., (2005), Oxytocin is Associated with Human Trustworthiness, Hormones and Behavior, no. 48, pp. 522-527. 